Copyright

by

Sara Ellen Gill

2015 
The Dissertation Committee for Sara Ellen Gill certifies that this is the approved version of the following dissertation:

Putting it into Context: Creating a Self-Report Measure of Big Picture Appraisal

Committee:

Stephanie Rude, Supervisor

Christopher McCarthy

David Drum

Barbara Dodd

Nancy Hazen-Swann 


\title{
Putting it into Context: Creating a Self-Report Measure of Big Picture Appraisal
}

by

\section{Sara Ellen Gill, B.A.; M.A.}

\author{
Dissertation \\ Presented to the Faculty of the Graduate School \\ of the University of Texas at Austin \\ in Partial Fulfillment \\ of the Requirements \\ for the Degree of \\ Doctor of Philosophy
}

The University of Texas at Austin

August 2015 


\section{Dedication}

This dissertation is dedicated in loving memory to my mother, Ellen McCamish Gill.

I would also like to dedicate this dissertation to Callie Cho, Eliza Cho, Cameron Gill, and Natalie Gill. Thank you for always helping me to see the big picture. 


\section{Acknowledgements}

I wish to thank the members of my committee: Dr. Stephanie Rude, Dr. Barbara Dodd, Dr. David Drum, Dr. Christopher McCarthy, and Dr. Nancy Hazen-Swann, for their support, flexibility, and generosity. I would like to give a special thank you to Dr. Stephanie Rude, my committee chair, for her countless hours providing encouragement and feedback throughout this process. Additionally, I would like to thank Dr. Barbara Dodd for her guidance and patience as I navigated the world of statistics.

There are countless people who have made this process both possible and rewarding. My father, Bedford Gill, has always encouraged me and for that I thank him. Throughout my lifetime, my brother, David Gill, has provided me with support, prodding, cajoling, and reassuring me as needed. His wit and wisdom have taught me more than I can say, and without him none of this would have been possible. My godmother, Nancy Scanlan, has modeled for me what it is to go above and beyond when giving to others. I will be forever grateful for all of her generosity.

Over the past six years, Laura and Ken Cho provided me with not only a home, but a family that served as my home base. They were unflagging in their support, often providing me with an ear, a shoulder, and/or a family meal. Through Laura I gained an older sister who never fails to inspire me with her caring intelligence, determination, and strength. In Ken I gained a second brother who has shown me the importance of flexibility and perseverance, as well as the power of red pants. I am beyond thankful to both of you. 


\title{
Putting it into Context: Creating a Self-Report Measure of Big Picture Appraisal
}

\author{
Sara Ellen Gill, Ph.D. \\ The University of Texas at Austin, 2015 \\ SUPERVISOR: Stephanie Rude
}

Big picture appraisal is a way of thinking about a negative or distressing event that involves developing a wider perspective, including the context of the event. Five facets have been proposed for big picture appraisal: an extended time perspective; the broader context of one's life; the broader human context; growth and learning; and, acceptance. This form of appraisal has previously been found to be associated with decreased levels of distress when an individual is processing an emotionally painful event. An initial pool of items was created using theory, an informal focus group, a pilot study, and interviews. An exploratory factor analysis was performed, with results indicating a single-factor solution. A second data collection was completed for the purposes of performing a confirmatory factor analysis. Construct validity was explored in both studies through the administration of multiple measures. Additionally, test-retest reliability and predictive validity were explored in the second study. Results regarding internal validity of the measure were inconsistent. Evidence was found indicating that big picture appraisal is a multifaceted construct, related to other positive emotion regulation strategies. 


\section{Table of Contents}

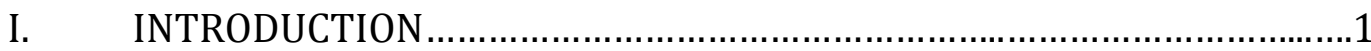

II. DATA COLLECTION: ITEM GENERATION, STUDY 1, AND STUDY $2 \ldots \ldots 8$

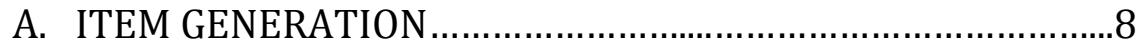

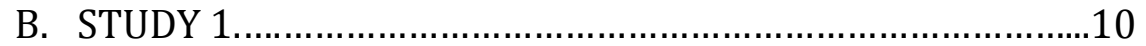

a. Introduction........................................................10

b. Method....................................................................11

c. Results and Discussion.............................................15

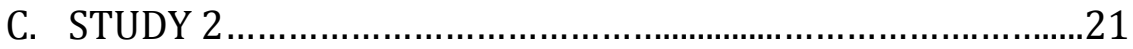

a. Introduction..........................................................21

b. Method................................................................23

c. Results and Discussion..........................................27

III. GENERAL DISCUSSION.............................................

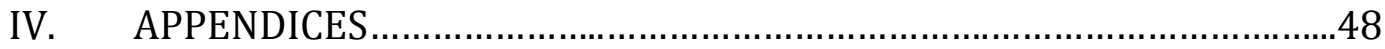

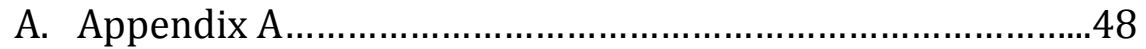

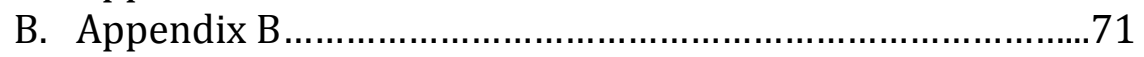

C. Appendix C .....................................................................

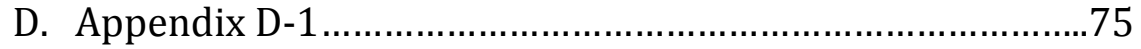

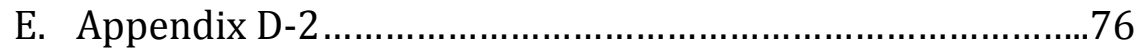

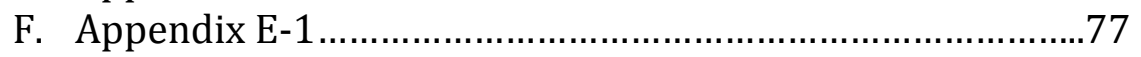

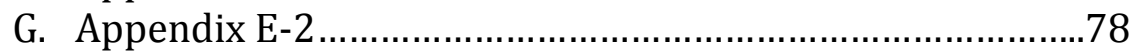

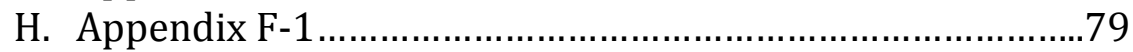

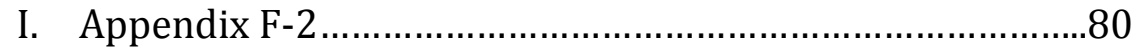

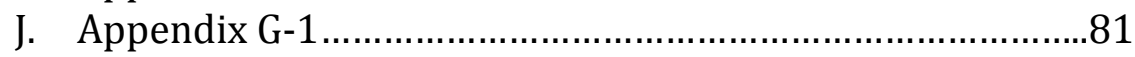

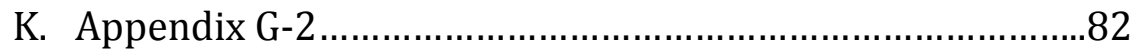

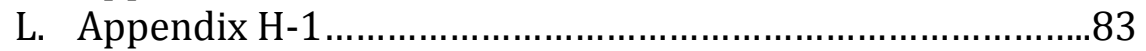

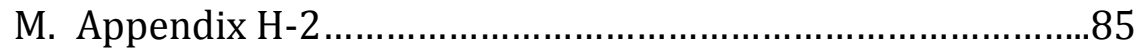

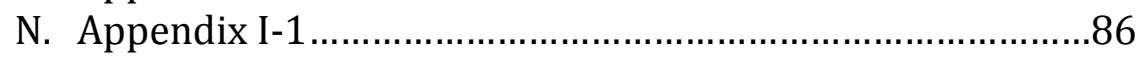

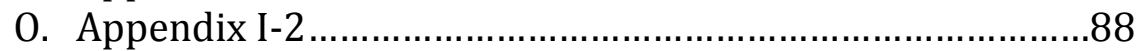

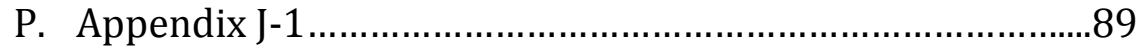

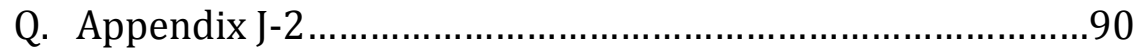

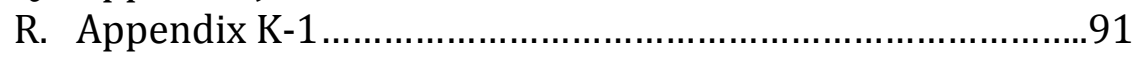

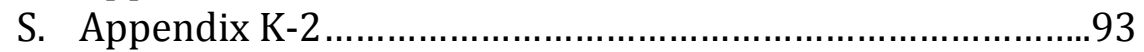

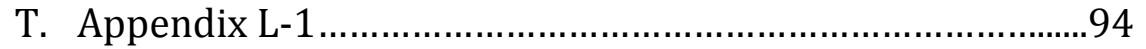

U. Appendix L-2 ………………………………..................

V. Appendix M-1 ……..........................................................

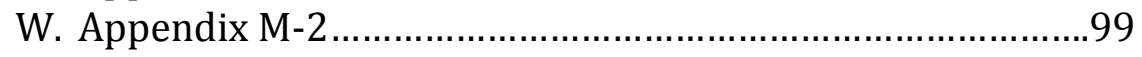




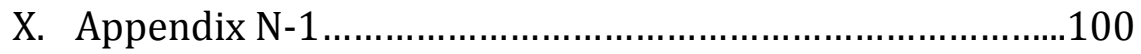

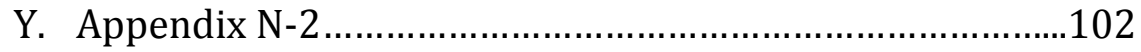

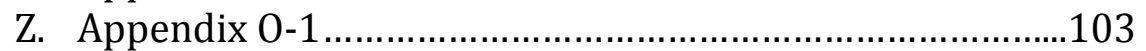

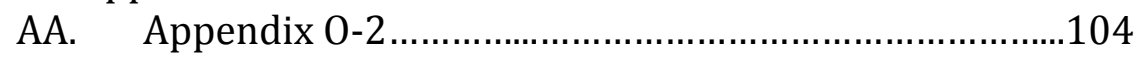

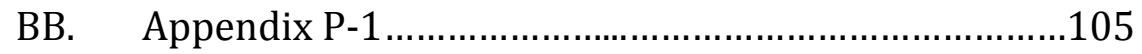

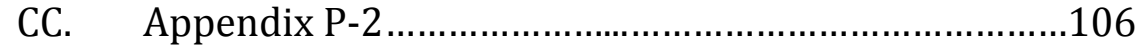

DD. Appendix R-1.....................................................10

EE. Appendix R-2 .......................................................109

FF. Appendix S-1..................................................... 110

GG. Appendix S-2 .........................................................111

V. REFERENCES ................................................ 112 


\section{Introduction}

Recent research has found that specific emotion regulation strategies are linked to both the development of various psychopathologies, as well as to improved positive mental health outcomes (Aldoa, Nolen-Hoeksema, \& Schweizer, 2010). Practitioners are incorporating these research findings into applied interventions so as to develop more effective treatment for mental health disorders such as borderline personality disorder, depression, and anxiety (Aldoa et al., 2010; Hayes, et al., 1999; Linehan, 1993; Teasdale, Segal, Williams, Ridgeway, Soulsby, \& Lau, 2000).

Emotion regulation is defined in several ways; however, the core of these definitions is the description of emotion regulation as a process whereby individuals try to change their emotional states. These efforts may happen consciously or unconsciously, they may be targeted at increasing or decreasing the emotion, and they may be used for regulating positive or negative emotions (Gross, 1998b; Koole, 2009).

Several studies have found that suppression, avoidance, and rumination are related to the development of depression, anxiety, substance abuse disorders, and eating disorders (for review see Aldoa et al., 2010). Reappraisal, problem solving, and acceptance have been linked to individuals experiencing more positive emotions and fewer negative emotions, as well as lower levels of depression and anxiety (Aldoa et al., 2010; Hill \& Updegraff, 2011). Reappraisal, in particular, has been extensively researched and has been shown to be an effective emotion regulation strategy (Aldoa et al., 2010; Gross, 1998). 
Reappraisal has been defined as an individual's ability to shift his or her perspective of a situation or event in order to change the resulting emotional experience (Gross \& John, 2003; McRae et al., 2012). Research indicates that reappraisal is a complex cognitive process that involves the use of executive functions and activates various parts of the brain as individuals try to regulate their emotions (Bebko, Franconeri, Ochsner, \& Chiao, 2011; McRae et al., 2012). There is evidence that this cognitive process effectively regulates emotional reactions - the early intervention in the cognitive processing of an event means that the individual does not need make extensive use of his or her cognitive resources (Gross and Thomposon, 2007). Building on this knowledge, researchers are now starting to focus on what types of reappraisals are most effective.

Several different lines of research have begun to explore reappraisals that involve the concept of individuals regulating their emotions by incorporating the larger context. Big picture appraisal has been defined as a way of thinking about a negative or distressing event by developing a wider perspective regarding the context of the event. This wider perspective incorporates the larger situation and the larger time perspective for the given emotional event (Rude, 2011). It is a type of cognitive reappraisal as it encourages the individual to shift how he or she is thinking about an experience. Additionally, it incorporates an individual's awareness of how his or her needs and experiences are similar to the needs and experiences of other people (Rude, 2011). Big picture appraisal appears to be similar to concepts of self-distancing, imagery perspective, and perspective broadening (Kross et al., 2005; Libby et al., 2011; Rude, 2011; Shartau et al., 2009). 
It has been theorized that big picture appraisal incorporates three different categories of thought processes (Rude, 2011). The first category is labeled "An extended time perspective" and involves an awareness that emotions change over time, and that as one gets more temporal distance from a negative event his or her distress lessens. The second category, "The broader context of one's life," includes the use of an awareness or perspective that one's life involves both positive and negative experiences. Finally, "The broader human context," uses a perspective that incorporates ideas that everyone faces adversity and distress, and that all humans have the same fundamental wants, needs, and goals (Rude, 2011). Two additional facets of big picture appraisal have been proposed based on information gathered from an informal focus group and interviews. "Growth and learning" incorporates the idea that individuals will often attempt to view a difficult situation as something from which they might learn a valuable lesson, or grow as a person. "Acceptance" involves the ability of individuals to acknowledge, rather than resist, a situation and the corresponding emotional reactions.

Researchers have begun to examine the use of big picture appraisal and the impact it has on mental health, particularly in relation to emotion regulation. In one study, participants were asked to write about a recent rejection experience using contextual questions or analytical questions. Approximately one week after the writing task, participants who were given questions consistent with big picture appraisal indicated they were experiencing lower levels of rumination and depressive symptoms compared to participants in the analytical question group and the no writing control group (Rude, Mazzetti, Pal, \& Stauble, 2011). Another study found similar results. Baum and 
Rude (2013) found that when big picture appraisal instructions were added to general expressive writing instructions, participants showed lower depressive symptoms compared to a control group.

Researchers have also investigated the possibility of using implicit strategies to teach individuals to use big picture appraisal and the possible impact of those strategies on their thinking (Miller, Rude, \& Haner, 2015). Participants were given a cognitive bias modification task. They were assigned to complete tasks based on one of two series of vignettes that either implicitly trained them to think in a manner consistent with big picture appraisal or in a manner consistent with evaluative thinking. Following a stressor task, the individuals in the big picture appraisal group were found to have a less negative mood compared to individuals in the evaluative group (Miller, Rude, \& Haner, 2015). These findings provide preliminary support for big picture appraisal as an effective emotion regulation strategy when used by individuals reflecting on an emotionally distressing event.

Other constructs similar to big picture appraisal have been proposed, namely selfdistancing, imagery perspective, and perspective broadening. Self-distancing has been described as a person being able to view an emotionally distressing event that has occurred as if he or she is a fly on the wall (Ayduk \& Kross, 2010). Studies have found that individuals using a self-distanced, as opposed to a self-immersed, perspective to process a negative emotional event experienced less distress (Kross \& Ayduk, 2008; Kross et al., 2005). Self-distancing has also been associated with decreased rumination, increased problem solving, and, when individuals are angry, reduced aggressive thoughts 
(Ayduk \& Kross, 2010; Kross \& Ayduk, 2008; Kross, Gard, Deldin, Clifton, \& Ayduk, 2012).

Similarly, researchers have proposed that the use of imagery perspective affects how an individual processes an emotional event. In a series of studies, participants were asked to view an event from either a first-person or a third-person perspective (Libby, Valenti, Pfent, \& Eibach, 2011; Valenti, Libby, \& Eibach, 2011). It was theorized that by taking a third-person perspective the individual would focus less on the concrete aspects of the experience and more on the overall context of the event (Libby et al., 2011; Valenti, et al., 2011). Researchers have found that the use of imagery perspective does have an impact on how individuals process their emotional experiences; however, the exact outcomes differ based on variables such as the individual's self-esteem and the type of emotion being processed (Libby et al., 2011; Valenti et al., 2011).

In addition to self-distancing and imagery perspective, perspective broadening is a concept that has been used to encourage people to take a larger view of a situation when they are presented with information that provokes strong emotions (Shartau, Dalgleish, \& Dunn, 2009). Shartau and colleagues have proposed four themes: every cloud has a silver lining; broader perspective; time heals; and, bad things happen. Findings indicate that when participants are able to take a different view of an emotionally evocative stimulus using one of these themes, they are less emotionally reactive (Shartau et al., 2009).

While the different types of perspective, from self-distancing to imagery perspective, employ different terminologies and definitions, they do point to general trends in the use of these emotion regulation strategies. Specifically, researchers have 
found that individuals often benefit from the ability to look at an emotional event as part of a larger picture. Self-distancing, imagery perspective, and perspective broadening have all been associated with positive mental health outcomes such as lower levels of depression and anxiety, and increased life satisfaction (Kross et al., 2005; Libby et al., 2011; Shartau et al., 2009).

Although the preliminary evidence shows that big picture appraisal and related constructs are effective emotion regulation strategies, research efforts have been limited by the lack of a consistent measure of these constructs. The creation of a self-report measure will allow researchers to validate the construct and provides them with a needed strategy to evaluate the impact of big picture appraisal in individuals. A self-report measure will allow researchers to better establish the theorized relationships between big picture appraisal and related constructs such as mindfulness. It would allow researchers to more accurately assess individual differences in big picture appraisal after the use of interventions, and to assess naturally occurring individual differences.

\section{Summary of Data Collection}

In order to create and evaluate the psychometric properties of a self-report measure of big picture appraisal, a series of data collections was completed. First, a large pool of items was created based on a focus group, several informal interviews, and conceptual discussions that helped the researchers refine and articulate the concept of big

picture thinking. In Study 1, the initial pool of items was administered to a large number of research participants for the purpose of completing an exploratory factor analysis, ultimately resulting in the retention of a single factor containing 23 items. Items were 
included from all of the proposed facets of big picture appraisal and were thought to be representative of the construct. Based on these results, a confirmatory factor analysis was performed in Study 2. Study 2 also assessed the test-retest reliability, and participants' scores in both data collections were correlated with their scores on a range of other measures to assess the construct and predictive validity of the measure. 


\section{Data Collection: Item Generation, Study 1, and Study 2}

\section{ITEM GENERATION}

The following steps taken for item creation were based on established recommendations concerning the use of literature review, naturalistic inquiry, and focus groups in instrument development (Pett, Lackey, \& Sullivan, 2003). An initial pool of 40 items was written based on the theory of big picture appraisal as articulated in Rude (2011) and on information gathered through a focus group. Participants in the focus group were asked a series of open-ended questions regarding negative emotional events and the different strategies they used to cope with these situations. They were then presented with information on big picture appraisal and asked to provide feedback and pertinent personal examples. This was done in an effort to ensure that individuals could relate to big picture appraisal as it was conceptualized, as well as to gather information regarding naturalistic language used to discuss pertinent concepts in order to guide how items would be written.

Using a pilot study, item-specific feedback, and interviews, the 40 items were evaluated to gather additional information on both the items and the construct of big picture appraisal. For the pilot study, 168 undergraduate students responded to the items, allowing for item reliability scores to be calculated. This information was used to provide preliminary evidence that the proposed items had an acceptable level of internal consistency. Regarding item-specific feedback, a convenience sample of 13 individuals was asked, either in person or online, to comment on the clarity of the items and the directions that would be given to other participants. Individual interviews were 
conducted by three researchers using a convenience sample of three participants. The purpose of these interviews was to both determine if the conceptual categories proposed were consistent with how individuals discussed coping with emotionally distressing events, as well as to gather information regarding other possible categories. Participants were asked to reflect on an emotionally distressing event. They were then prompted to talk in detail about whether they felt the issue had been resolved and what thought processes they had experienced while trying to cope with, and process, the chosen situation.

The information gathered through these steps was then used to identify problematic items in the existing pool, as well as to generate new items. Based on themes that reoccurred during the individual interviews and focus group, two possible additional dimensions were proposed to big picture appraisal: "Acceptance" and "Growth and learning." The five dimensions were defined as follows. "An extended time perspective," incorporates the effect of time in lessening distressing emotions. "I know that my perspective is going to change with time," is one item used to assess this category. "The broader context of one's life," indicates the use of an awareness or perspective that one's life includes both positive and negative experiences. Items such as, "I remember that other aspects of my life are going better," were included in this category. "The broader human context," incorporates the idea that everyone faces adversity and distress, and humans fundamentally have the same wants, needs, and goals. This was assessed through items such as, "I remind myself that painful experiences are a part of everyone's life." "Acceptance," refers to an individual's attempt to accept his or her emotional 
reactions. One such item is, "I accept the situation and my reactions to it." "Growth and learning," represents the individual's sense that he or she is able to learn and grow from difficult situations. For example, "It feels like I will be wiser from this," is one item from this category. Based on these categories, a final pool of 54 items was written, which was then used in an exploratory factor analysis.

\section{STUdy 1: Exploratory FACTOR ANALYSIS AND ExAMination OF CONVERGENT AND DISCRIMINANT VALIDITY}

The purpose of Study 1 was to select items developed to measure big picture appraisal, to create a self-report measure, and to gain further understanding of the structure of big picture appraisal. This was done both by examining the factor structure and reducing the number of items, as well as collecting preliminary data examining convergent and discriminant validity.

Discriminant validity was assessed through the short form of the Marlow-Crowne Social Desirability Scale and the Positive and Negative Affect Schedule or PANAS (Ballard, 1992; Watson, Clark, \&Tellegen, 1988). The social desirability scale assesses whether participants tried to provide responses that would be considered socially desirable. It was hypothesized that no significant correlation would be found. The PANAS was used to examine whether participants' moods were significantly related to their responses on the big picture appraisal items. No significant relationship was expected.

Concerning convergent validity, big picture appraisal and self-compassion appear to be similar in their inclusion of the concept of the commonality of human experiences 
and the acceptance of emotions. Therefore, it was hypothesized that scores on the SelfCompassion Scale (Neff, 2003) would be positively correlated with scores on the measure of big picture appraisal. Similarly, because big picture appraisal is considered to be a type of cognitive reappraisal, it was expected to have a positive correlation with the reappraisal subscale of the Emotion Regulation Questionnaire (Gross \& John, 2003). Additionally, big picture appraisal was hypothesized to correlate with the openness subscale of the Big Five Inventory (John, Donahue, \& Kentle, 1991). A relationship was expected as both constructs refer to an individual's ability to be open to, or curious about, a range of perspectives.

Employing big picture appraisal as an emotion regulation strategy has been theorized to decrease rumination and to be inconsistent with suppression. Therefore, it was hypothesized that scores on measure of big picture appraisal would show moderate negative correlations with scores on measures of rumination and suppression. It was also hypothesized that participants' scores on the big picture appraisal measure would have a negative correlation with the neuroticism subscale of the Big Five Inventory (John, Donahue, \& Kentle, 1991) but it was hoped that the correlation would be relatively low, indicating the measurement of a construct distinct from neuroticism.

\section{Method}

\section{Participants}

The survey was administered to a total of 827 students recruited from the subject pool of a large western university. Data collection occurred over two semesters: 580 participants completed the survey during the first semester, while 247 students completed 
the survey during the second semester. Of the total number of participants, 277 were male and 550 were female. Participants provided the following information regarding their race and ethnicity: 0.8\% identified as African-American; $25.6 \%$ identified as Hispanic-American or Latino; $0.1 \%$ identified as Native-American; $22.4 \%$ identified as Asian-American; 43.9\% identified as Caucasian; 1.6\% identified as Middle Eastern; $4.0 \%$ identified as multiracial; and, $1.6 \%$ identified as other.

\section{Procedures}

A pool of 54 items was administered to the participants, who completed the survey via computer. The participants were informed of the purpose of the study, and their consent to participate was obtained. All participants were given a series of demographic questions, the short-form of the Marlow-Crown Social Desirability Scale, the Positive and Negative Affect Schedule, and the 54 big picture appraisal items. In addition, they completed measures of emotion regulation and personality.

\section{Measures}

All of the measures administered during this study are available in the appendices of this dissertation.

Demographic Questionnaire. A series of items assessing participants' gender, race, age, class standing, and family household income level were given.

Social Desirability. A short form of the Marlow-Crowne Social Desirability Scale proposed by Ballard (1992) was used as an alternative to the full scale. The composite scale has previously been found to be preferable to the full version, as it has fewer items and has a similar level of reliability (Crowne \& Marlow, 1960; Loo \& 
Loewen, 2004). The items of this scale examine whether a participant is likely to answer questions with a positive bias, meaning they try to answer questions in a way that is consistent with what is considered to be more socially acceptable. For this measure, high scores indicate an increased level of socially desirable responses being given.

Positive and Negative Affect Schedule (PANAS). The Positive and Negative Affect Schedule (PANAS) is a widely used measure that assesses affective states (Watson, Clark, \& Tellegen, 1988). Twenty different emotions are listed, and the individual is asked to indicate the extent to which they have experienced that emotion using a 5-point Likert-type scale. Half of the items represent negative affect, (e.g. "Distressed") and the other half of the items represents positive affect (e.g. "Excited). For both subscales, higher scores represent higher levels of the given affect.

The Big Five Inventory (BFI). The Big Five Inventory (BFI) is a self-report measure of the five major facets of personality, which include extraversion, agreeableness, conscientiousness, neuroticism, and openness (John, Donahue, \& Kentle, 1991). Compared to other personality inventories, the BFI is relatively short. It has been found to have a high rate of internal consistency (Cronbach's alpha of .83), as well as it has been found to be highly correlated with similar personality inventories, such as the NEO Personality Inventory (NEO-PI) (John, Naumann, \& Soto, 2008). Higher scores on the subscales represent increased levels of the trait.

Emotion Regulation Questionnaire (ERQ). The Emotion Regulation Questionnaire (ERQ) was created to assess suppression and reappraisal (Gross \& John, 2003). It consists of 10 items that are answered using a 7-point Likert scale, which 
ranges from strongly disagree to strongly agree. The emotional suppression subscale includes items such as, "I control my emotions by not expressing them." The reappraisal subscale includes items such as, "I control my emotions by changing the way I think about the situation I am in." Gross and John (2003) indicate that both subscales as having good internal consistency, reporting that the suppression subscale has a Cronbach's alpha of .73 and that the reappraisal subscale has a Cronbach's alpha of .79. They also demonstrated satisfactory convergent and discriminate validity with measures of inauthenticity, mood regulation, coping, and personality (Gross \& John, 2003). For both subscales, high scores represent increased use of either suppression or reappraisal. Ruminative Response Scale (RRS). The Ruminative Response Scale (RRS) is a subscale of the Response Style Questionnaire (RSQ; Nolen-Hoeksema \& Morrow, 1991). It is a 22-item self-report inventory that examines responses to a depressed mood, with items focused on the self, symptoms, or consequences of the mood. For example, items include "Think about how alone you feel" and "Analyze recent events to try to understand why I am depressed," with answer choices ranging from "almost never" to "almost always," with high scores representing increased use of rumination. It has been shown to have good internal consistency, with a Cronbach's alpha of .89.

Self-Compassion Scale (SCS). The Self-Compassion Scale is a self-report measure that was constructed to assess one's level of self-compassion. It includes six subscales: self-kindness, self-judgment, common humanity, isolation, mindfulness, and over-identification. Participants respond to items such as, "I try to be understanding and patient towards those aspects of my personality I don't like" using a 5-point Likert scale 
ranging from "almost never" to "almost always," with high scores representing higher levels of self-compassion. It was found to have a high level of internal consistency with a Cronbach's alpha of .92 (Neff, 2003).

\section{Results and Discussion}

A principal axis factor analysis was performed using a Promax rotation with Kaiser normalization. Multiple selection criteria, including eigenvalues greater than one and a scree plot, were examined to try to determine the number of factors to be retained. This is consistent with the recommended practices for scale development (Netemeyer et al., 2003). Nine factors were indicated based on an eigenvalue greater than one, and two factors were indicated based on the scree plot, which can be seen below in Figure 1. Table 1 below shows the total variance explained by these two factors. However, after the two-factor solution was examined, only the first factor, which consisted of 23 items, was retained. This choice was made due to the second factor consisting only of negatively worded items that appeared to be consistent with a measure of depression. As can be seen in the Table 2, the first factor contained items from all of the proposed subscales. The single factor was judged to be representative of the construct of big picture appraisal, and was used to create the Big Picture Appraisal Questionnaire (BPAQ). Due to the number of items with significant factor loadings, all retained items had a factor loading greater than or equal to 0.5 , putting them in the "very significant" range (Netemeyer, Bearden, \& Sharma, 2003). The retained factor was found to have a high level of internal consistency with a Cronbach's alpha of .91. 
Table 1: $\quad$ Total Variance Explained by the Two Initial Extracted Factors of the Big Picture Appraisal Scale.

\begin{tabular}{lcccccc}
\hline Factor & \multicolumn{3}{c}{ Initial Eigenvalues } & \multicolumn{3}{c}{ Extracted Sum of Squares Loadings } \\
\cline { 2 - 7 } & Total & $\begin{array}{c}\text { Percent } \\
\text { Variance }\end{array}$ & $\begin{array}{c}\text { Cumulative } \\
\text { Percent }\end{array}$ & Total & Percent & Cumulative \\
Variance & Percent \\
\hline 1 & 13.73 & 25.42 & 25.42 & 13.73 & 25.42 & 38.63 \\
2 & 7.67 & 14.20 & 39.63 & 7.67 & 14.20 & 39.63 \\
\hline
\end{tabular}

Figure 1: Scree Plot of Exploratory Factor Analysis of 53 Items for Big Picture Appraisal Questionnaire.

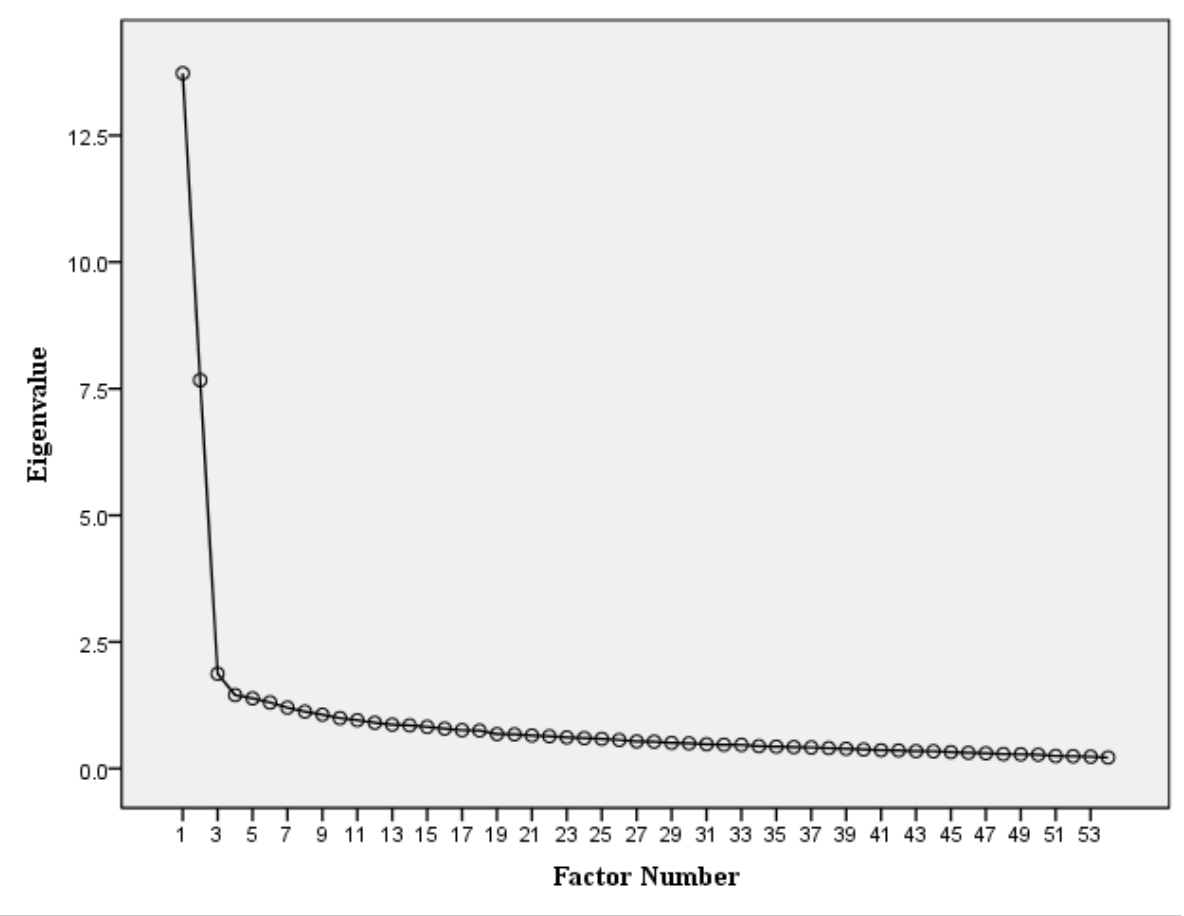


Table 2: $\quad$ Factor Loadings for Exploratory Factor Analysis with Promax Rotation and a Two-Factor Solution of the Big Picture Appraisal Questionnaire.

\begin{tabular}{|c|c|c|}
\hline \multirow[b]{2}{*}{ Item } & \multicolumn{2}{|c|}{ Factor Loadings } \\
\hline & Factor 1 & Factor 2 \\
\hline $\begin{array}{l}\text { I remind myself that if I just wait it out, I will } \\
\text { eventually feel better }\end{array}$ & .40 & -.13 \\
\hline $\begin{array}{l}\text { I remember that other aspects of my life are going } \\
\text { better. }\end{array}$ & .48 & -.25 \\
\hline I see myself as disconnected from other people. & .05 & .56 \\
\hline I accept the situation and my reactions to it. & .38 & -.22 \\
\hline I struggle against the situation or my feelings. & .09 & .47 \\
\hline $\begin{array}{l}\text { I remind myself that I will grow from this } \\
\text { experience. }\end{array}$ & .66 & -.02 \\
\hline I know that other areas of my life are going okay. & .54 & -.22 \\
\hline I do not trust that I will ever feel better. & -.12 & .55 \\
\hline $\begin{array}{l}\text { I remind myself that painful experiences are a part of } \\
\text { everyone's life. }\end{array}$ & .70 & .088 \\
\hline I know I will be able to come to terms with this. & .59 & -.10 \\
\hline $\begin{array}{l}\text { It seems like I will be changed for the worse by these } \\
\text { problems. }\end{array}$ & .04 & .54 \\
\hline $\begin{array}{l}\text { I know that my perspective is going to change with } \\
\text { time. }\end{array}$ & .49 & .11 \\
\hline I feel isolated. & -.00 & .66 \\
\hline $\begin{array}{l}\text { I reflect on how people I know have gone through } \\
\text { similar situations. }\end{array}$ & .56 & .09 \\
\hline $\begin{array}{l}\text { There are things about my feelings that seem bad or } \\
\text { shameful. }\end{array}$ & .16 & .55 \\
\hline I know this situation will teach me things. & .69 & .00 \\
\hline $\begin{array}{l}\text { I understand that the situation will look different to } \\
\text { me after some time passes. }\end{array}$ & .64 & .03 \\
\hline $\begin{array}{l}\text { I cannot help but notice a pattern of negative } \\
\text { behavior in my life. }\end{array}$ & .05 & .66 \\
\hline I feel like I cannot be as open to life after this. & -.00 & .61 \\
\hline It feels like I can live with this. & .38 & -.17 \\
\hline I view this as part of life's lessons. & .68 & -.08 \\
\hline I stay aware of what I can do well. & .52 & -.18 \\
\hline I find inspiration in other people's experiences. & .57 & -.04 \\
\hline $\begin{array}{l}\text { It seems bad to let myself think too much about the } \\
\text { problems I am having. }\end{array}$ & .30 & .10 \\
\hline It feels like I will be wiser from this & .67 & -.01 \\
\hline I lose perspective about better times. & -.06 & .59 \\
\hline I realize that this is only part of who I am. & .49 & .07 \\
\hline
\end{tabular}


Table 2: $\quad$ Continued

I remind myself that what I am experiencing is

.61

something everyone feels.

I let myself experience my feelings.

I know there is value in painful experiences.

My problems feel worse than those of others.

I keep in mind that feelings change.

It seems like I am failing at everything.

I view my situation as worse than that of other

people.

I remind myself that I have felt this bad before and come out of it.

I know this is only part of my life.

I do not feel connected to others.

I feel I cannot stand these emotions.

I realize that I will learn from this.

I am aware that other people often feel the way that I

do.

I remind myself that suffering is part of life.

It seems like the strong emotions will never end.

I know there is value in experiencing my emotions

fully.

I view every part of my life negatively.

I remind myself that everyone suffers sometimes.

I lost my ability to think about positive things in my

life.

I know I will be less trusting after this.

I know that others share experiences like mine.

I forget that I will not always feel this bad.

I feel as if I am somehow separated from other people.

I believe that I will be more closed off after this.

I know that there are many ways to view the difficult situation.

It seems reasonable to feel the way I do.

Note. Factor loadings $>.50$ are in boldface.
.42

.70

.07

.62

$-.07$

$-.06$

.62

.00

.65

.04

.02

.70

$.06 \quad .70$

$.76-.02$

$\begin{array}{ll}.67 & -.02\end{array}$

$.69 \quad .11$

$.11 \quad .73$

$.65 \quad .15$

$-.16 \quad .62$

$.68 \quad .06$

$\begin{array}{ll}-.08 & .67\end{array}$

$\begin{array}{ll}.04 & \mathbf{5 8}\end{array}$

$.64-.01$

$.03 \quad .62$

$\begin{array}{ll}.08 & .77\end{array}$

$\begin{array}{ll}.03 & .69\end{array}$

$.59 \quad .04$

.36

.12

After the single-factor form was selected, participants' responses on the 23 items were added together for a total unit weighted score, which was then correlated with their scores on other measures administered. The correlations are presented in Table 3 . While a 
significant correlation was found between scores on the measure of big picture appraisal and scores on the social desirability scale, it is small and would not have been significant was the sample not so large (Ballard, 1992). Similarly, a small but significant correlation was found between the positive affect subscale of the PANAS and the big picture appraisal measure. Consistent with predictions, no significant correlation was found between the big picture appraisal measure and the negative affect subscale of the PANAS (Watson, Clark, \& Tellegen, 1988).

Concerning scales used to examine convergent validity, participants' scores on the BPAQ and their total scores on the SCS and the ERQ-Reappraisal subscale were found to have moderate positive relationships with one another (Gross \& John, 2003; Neff, 2003). Scores from the BPAQ and the BFI - Openness subscale were found to have a modest positive relationship with each other (John, Donahue, \& Kentle, 1991). These correlations are in the predicted direction and are consistent with the theoretical construct of big picture appraisal, providing validation of the construct and the measure. The small to moderate, positive correlations between the big picture appraisal measure and the SCS, the reappraisal subscale of the ERQ, and the openness subscale of the BFI demonstrate that big picture appraisal is related to the constructs being measured by these scales, as was previously hypothesized. However, the relationships are not so strong as to indicate that these scales are measuring the same construct.

Regarding the RRS, the BPAQ was found to have a weak correlation with the total score, indicating that big picture appraisal is not related to rumination. Additionally, the participants' scores on the BPAQ were found to have a weak correlation with the 
ERQ - Suppression subscale, providing evidence that big picture appraisal is not related to suppression. These results are inconsistent predications, as it was theorized that big picture appraisal would be negatively related to both rumination and suppression. The big picture appraisal measure demonstrated a weak but statistically significant negative correlation with the BFI - Neuroticism subscale; however, it is thought that this finding is significant due to the number of participants included and not due to the strength of the relationship. Therefore, this finding is considered to be consistent with the theory of big picture appraisal, and neuroticism and big picture appraisal do not appear to be strongly related.

Table 3: $\quad$ Correlations for Establishing Convergent and Discriminant Validity of the Big Picture Appraisal Questionnaire.

\begin{tabular}{cc}
\hline Scale & Big Picture Appraisal Questionnaire \\
\hline Social Desirability Scale & $.09^{*}$
\end{tabular}

Positive and Negative Affect Schedule $.27 * *$

Positive Subscale

Positive and Negative Affect Schedule $-.06$ Negative Subscale

Self-Compassion Scale

Emotion Regulation Questionnaire $.52 * *$ Reappraisal Subscale

Big Five Inventory - Openness Subscale

Ruminative Response Scale $-.01$

Emotion Regulation Questionnaire .01 Suppression Subscale

Big Five Inventory - Neuroticism Subscale $-.18^{* *}$ Note. ${ }^{*} p<.05 .{ }^{* *} p<.01$. 


\section{STUdy 2: CONFIRMATORY FACTOR ANALYSIS AND EXAMination OF CONSTRUCT}

\section{VALIDITY}

Study 2 had four goals: to assess the factor structure found in Study 1 for the big picture appraisal measure; to examine internal consistency; to address predictive validity; to gather additional information regarding construct validity; and, to assess the temporal stability of the measure by an approximately two-week retest.

A confirmatory factor analysis (CFA) was conducted to determine whether the single-factor structure retained in Study 1 is an accurate representation of the measure. Moreover, CFA provides a more reliably accurate assessment of internal consistency of the measure than is provided by Cronbach's alpha (Brown, 2006). The construct and predictive validity of the measure were also examined.

Big picture appraisal was found in Study 1 to be related to self-compassion, reappraisal, and openness. In Study 2, relationships with several other measures of similar constructs were explored. Two such constructs are decentering, an individual's ability to separate or gain distance from his or her experiences and feelings, and mindfulness, which entails bringing an open awareness to processing one's experience. Another related construct is cognitive flexibility, which would logically seem to be required in order to shift perspective toward big picture appraisal. Similarly, big picture appraisal would seem to require a relatively high level of construal. It was therefore expected that there would be a positive correlation between the BPAQ and the decentering subscale of the Experiences Questionnaire, the Mindfulness Attention Awareness Scale, the Cognitive Flexibility Inventory, and the Behavior Identification 
Form, which assesses the level of construal endorsed by the individual (Brown \& Ryan, 2003; Dennis and Vander Wal, 2010; Fresco et al., 2007; Vallacher and Wegner, 1989). A measure assessing overall use of emotion regulation strategies, the Difficulties in Emotion Regulation Scale, was included (Gratz \& Roemer, 2003). A negative convergent relationship was expected between the DERS and the BPAQ.

Predictive validity of the BPAQ was also assessed. Big picture appraisal has been theorized to exert a protective function for individuals experiencing adversity. Related to this, stressful life events have previously been found to be associated with the onset of depression (Lloyd, 1980). Given the theorized protective nature of big picture appraisal, it was predicted that big picture appraisal scores would moderate the relationship between scores on the short-form Center for Epidemiological Studies - Depression Scale and life stress scores as measured by the Social Readjustment Rating Scale (Cole, Rabin, Smith, \& Kaufman, 2004; Holmes and Rahe, 1967), with high scorers on the BPAQ showing an attenuated depressive response to life stress. To assess this, participants were given the big picture appraisal measure and the SRRS at Time 1, and completed the CESD-short form at Time 2 .

Last, test-retest reliability was examined by administering the 23 items assessing big picture appraisal at both Time 1 and Time 2. It was hypothesized that participants' scores across time would remain stable. 


\section{Method}

\section{Participants}

Participants for the study were recruited from the undergraduate population at a large western university. The study was completed over two semesters, with a total of 492 participants completing all measures given. Of these participants, 206 were male and 286 were female. They ranged in age from 18-45, with a median age of 21 years old. When asked to describe their race and ethnicity, 2.4\% identified as AfricanAmerican/Black, 19.5\% identified as Hispanic-American/Latino/Chicano, 19.5\% identified as Asian-American, 52\% identified as Caucasian/European-American, 1.6\% identified as Middle Eastern/Arab-American, 3\% identified as Multiracial, and 1.8\% identified as Other.

\section{Procedures}

The participants were informed of the purpose of the study, and their consent was obtained. Data collection occurred over two sessions. Time 1 and Time 2 took place approximately two weeks apart. In addition to the proposed measure, a series of measures was administered at Time 1 in order to help continue the process of establishing convergent validity, and a brief set of additional measures was administered at Time 2 to help establish predictive validity and test-retest reliability.

\section{Measures}

The BPAQ and all additional measures that were administered to participants in this study are available in the appendices of this document. 
Demographic Questionnaire - Time 1. A series of items assessing participants' gender, race, age, and other characteristics.

Big Picture Appraisal Questionnaire (BPAQ)-Time 1 and Time 2. This proposed measure of big picture appraisal is a self-report measure that contains items assessing an individual's ability to engage in "big picture" thinking when upset. Respondents answer using a 5-point Likert scale ranging from "never" to "very frequently." Based on the results of the exploratory factor analysis that was previously done, 23 items were retained on a single factor, with a Cronbach's alpha of .90. A higher score is thought to indicate an increased use of big picture appraisal.

Experiences Questionnaire (EQ) - Time 1. The Experiences Questionnaire is a self-report inventory that was designed to measure decentering and rumination (Fresco et al., 2007). It consists of a total of 20 items such as, "I am better able to accept myself as I am," and, "I think over and over again about what others have said to me," with high scores representing an increased level of the corresponding construct. While the measure consists of two subscales, decentering and rumination, only the decentering subscale will be examined for the purposes of this study. Internal consistency for the decentering subscale is high $(r=.81)$ (Fresco et al., 2007).

Cognitive Flexibility Inventory (CFI) - Time 1. The Cognitive Flexibility Inventory (CFI) was developed to measure an individual's ability to challenge his or her own cognitions and generate alternative explanations and solutions to difficult situations (Dennis and Vander Wal, 2010). This self-report measure consists of 20-items on two subscales: Alternatives and Control, with higher scores on the subscales representing a 
higher level of the given construct. The subscales have been found to demonstrate good levels of internal consistency with Cronbach's alpha levels ranging from .91 to .84 (Dennis and Vander Wal, 2010). Only the Alternatives subscale will be examined for the purposes of this study.

Behavior Identification Form (BIF) - Time 1. The Behavior Identification Form (BIF) is a 25-item self-report measure that was created to assess an individual's action identification level (Vallacher and Wegner, 1989). Participants are provided with a list of behaviors and then two different ways of describing each behavior. They are directed to choose the statement that best describes the behavior as they see it (Vallacher and Wegner, 1989). For example, when given the item "Attending class," participants are presented with the answer options of, "a) Sitting in a chair" and "b) looking at the blackboard." This scale has been shown to have high internal consistency, with a Cronbach's alpha of .85 (Vallacher and Wegner, 1989). High scores are thought to represent higher, or more abstract, levels of construal.

Mindful Attention Awareness Scale (MAAS) - Time 1. The Mindful Attention Awareness Scale (MAAS) is a 15-item questionnaire that is intended to measure dispositional mindfulness (Brown \& Ryan, 2003). Using a six-point Likert scale ranging from "almost always" to "almost never," participants rate how often they experience what is described in items such as, "I tend to walk quickly to get where I'm going without paying attention to what I experience along the way," and "I snack without being aware that I'm eating." A higher score is representative of a higher level of mindfulness. Brown and Ryan (2003) reported an internal consistency of .82 . 
Difficulties in Emotion Regulation Scale (DERS) - Time 1. The Difficulties in Emotion Regulation Scale (DERS) is a 36 item self-report questionnaire (Gratz \& Roemer, 2003). Using a 5-point scale ranging from "almost never" to "almost always," participants respond to items that assess six dimensions of emotion regulation, with higher scores indicating increased difficulties. These dimensions include: nonacceptance of one's negative emotions; difficulties accomplishing goals when experiencing negative emotions; difficulties remaining in control of one's behavior when experiencing negative emotions; lack of emotional awareness; low self-efficacy for regulating negative emotions; and, difficulty identifying and understanding emotions. The DERS has demonstrated a high internal consistency, with a Cronbach's alpha of .93. All subscales have a Cronbach's alpha greater than .80 (Gratz \& Roemer, 2003).

Social Readjustment Rating Scale (SRRS) - Time 1. The Social Readjustment Rating Scale (SRRS) is used to assess the number of stressors an individual has experienced during the past year (Holmes and Rahe, 1967). Stressful events listed include the death of a spouse, changes in financial status, and changes in work or school. Each event is weighted based on the level of stress thought to be associated with it. These weighted scores are then added together to give the student an overall stress score, with higher scores representing a higher level of life stress.

Rasch-Derived Center for Epidemiologic Studies - Depression Scale Short Form (short-form CES-D) - Time 2. This short form of the Center for Epidemiologic Studies Depression scale (short-form CES-D) was derived from the full-form CES-D using a range of statistical techniques based on item response theory (Cole, Rabin, Smith, \& 
Kaufman, 2004). It is a ten-item self-report instrument used to assess for symptoms of depression. Participants use a 4-point Likert-type scale to respond to items such as, "I felt my life had been a failure," and, "I felt hopeful about the future." Higher scores represent increased symptoms of depression. It has been found to have good levels of internal consistency with Cronbach's alpha levels ranging from .75 to .82 .

\section{Results and Discussion}

\section{Confirmatory Factor Analysis}

A confirmatory factor analysis (CFA) was performed to assess the factor structure of the BPAQ. Based on the results of the EFA, it was hypothesized that the 23 items would comprise a single factor. The chi- square value for the overall model fit was significant, $X^{2}(230)=1492.074, \mathrm{p}<.0001$ suggesting that the data did not fit the hypothesized model. In addition to $X^{2}$, other fit indices were assessed due to the sensitivity of $X^{2}$ in large samples (Kline, 1998). Examination of these indices showed poor model fit as well, with CFI $=.785$, RMSEA $=.103$, SRMR $=.066$.

The lack of fit found is in contrast to the Cronbach's alpha found in Study 1, as well as a Cronbach's alpha of .94, calculated using the current data set. This can best be attributed to CFA being a more accurate way to assess the internal consistency of a measure. Due to the single factor model, it is hypothesized that the poor fit is a result of too few factors having been found in the EFA. This can be caused by the inability of EFA to account for correlated errors. If two or more items have variance caused by the same source of error, meaning they are related outside of the latent construct being 
measured, EFA is not able to incorporate this when the factor structure is examined. This can then cause items to appear more related than is otherwise true, leading to results indicating fewer factors than is accurate. This hypothesis is based in part on the finding of an additional analysis that was performed, which indicated that a model incorporating multiple factors may better fit the data.

\section{Correlations Between Measures}

In order to assess construct validity, a series of Pearson's correlation coefficients were calculated between the BPAQ and the BFI, the DERS, the MAAS, the BIF, the EQ, and the CF. The correlations can be seen in Table 3. Participants' scores on the BPAQ and their scores on the decentering subscale of the EQ and the CFI-Alternatives subscales were found to have a moderate positive relationship (Dennis and Vander Wal, 2010; Fresco et al., 2007). Scores from the BPAQ and the BIF were found to have a modest positive relationship with each other (Rosenberg, 1989; Vallacher and Wegner, 1989). Additionally, a moderate negative relationship was found between scores on the big picture appraisal measure and the DERS (Gratz \& Roemer, 2003).

The correlations are in the predicted direction and are consistent with the theoretical construct of big picture appraisal, providing validation of the construct. The small to moderate, positive correlations with the EQ, CFI, and BIF, demonstrate that big picture appraisal is related to the constructs being measured by these scales, as was hypothesized. However, the relationships are not so strong as to indicate that these scales are measuring the same construct. The BPAQ demonstrated a moderate negative correlation with the DERS, which is consistent with the hypothesis that individuals who 
engage in big picture appraisal are better able to regulate their emotions. The BPAQ was found to have only a weak correlation with scores on the MAAS, although it was in the predicted direction. This may in part be due to differences in the items, as the MAAS includes multiple items emphasizing present moment sensory awareness, giving the measure a different emphasis in comparison to items examining big picture appraisal.

Table 4: $\quad$ Correlations for Establishing Convergent and Discriminant Validity of the Big Picture Appraisal Questionnaire.

\begin{tabular}{lc}
\hline \multicolumn{1}{c}{ Scale } & Big Picture Appraisal Questionnaire \\
\hline $\begin{array}{l}\text { Experiences Questionnaire (EQ) - } \\
\text { Decentering Subscale }\end{array}$ & $.45^{* *}$ \\
$\begin{array}{l}\text { Cognitive Flexibility Inventory (CFI)- } \\
\text { Alternatives Subscale }\end{array}$ & $.32^{* *}$ \\
Behavior Identification Form (BIF) & $.24^{* *}$ \\
$\begin{array}{l}\text { Mindful Attention Awareness Scale } \\
\text { (MAAS) }\end{array}$ & .14 \\
$\begin{array}{l}\text { Difficulties in Emotion Regulation } \\
\text { Questionnaire (DERS) }\end{array}$ & $-.30^{* *}$ \\
\hline Note. ${ }^{* *} p<.01$. &
\end{tabular}

To assess the predictive validity of the measure of big picture appraisal participants' scores on the SRRS and the BPAQ were entered in the first step of the regression, but did not account for a significant amount of variance in participants' scores on the CES-D, $R^{2}=.01, F(2,489)=1.81, p=.16$. The interaction term between big picture appraisal and stressful life events was added to assess the interaction between these two variables on depression. Results were significant, $\Delta R^{2}=.01, \Delta F(1,488)=$ $5.12, p=.02$, suggesting that big picture appraisal moderates the impact of life stressors on participants' depression scores. However, it should be noted that the effect is small, 
with only approximately one percent of the variance accounted for by this interaction. Further, the full model, including both first order and interaction effects accounted for only two percent of the variance in CES-D scores.

The interaction was decomposed by treating participants' scores on the big picture appraisal measure as a binary moderator, with cases selected based on whether they fell into the top or bottom third of scores. As predicted, for participants who scored higher on the BPAQ the relationship between life stress and depression was attenuated.

Figure 2: Two-way binary interaction of participants' depression scores with low or high life stress scores, as moderated by high or low scores of big picture appraisal.

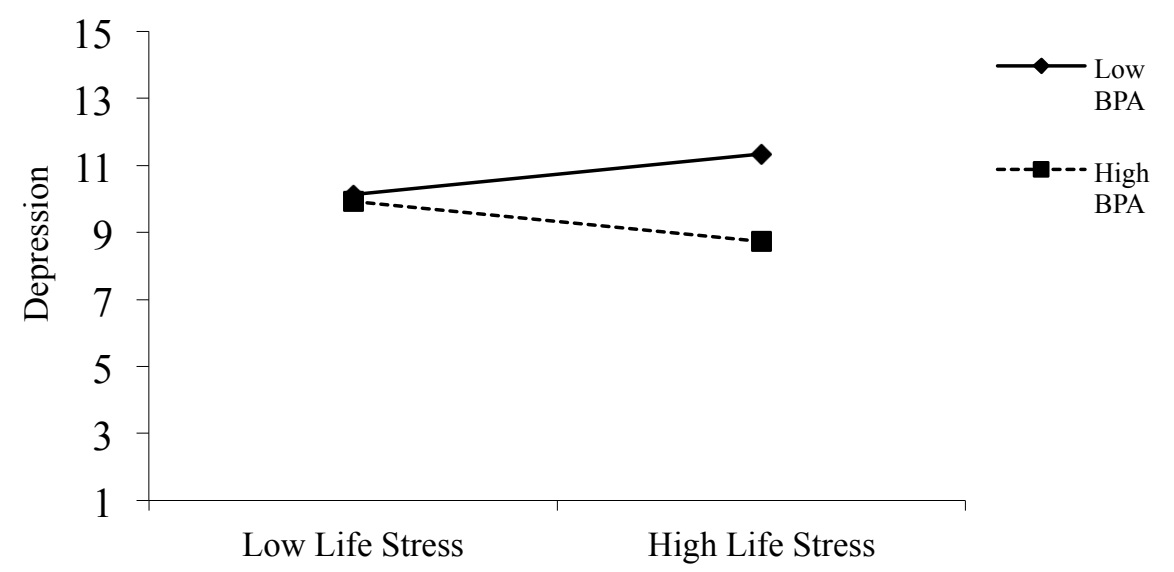

Test-retest reliability was assessed between participants' scores on the BPAQ at Time 1 and participants' scores on the measure at Time 2, which participants completed approximately two weeks apart. Results indicate adequate stability in scores $(r=.73, p=$ .01 ), thus providing further evidence that the scale demonstrates temporal stability.

\section{Additional Analysis}

Due to the poor fit found in the initial CFA, an EFA was performed in order to help determine possible causes. Principal axis factor analysis with Promax rotation, a 
type of oblique rotation, with Kaiser normalization was performed using the 23 items. Using the criteria of eigenvalues equal to or greater than one, a three-factor solution was indicated, with all of the factors found to be correlated. The scree plot, shown in Figure 3, appeared to be ambiguous, indicating either a two or three-factor solution. The threefactor solution was selected in an effort to ensure that all dimensions were captured for further exploration. Individual items were retained if their factor loading was equal to or greater than .4 , as items loadings meeting this requirement are viewed as sufficient (Netemeyer et al., 2003). Based upon this criterion, the first factor consisted of ten items $(\alpha=.90)$, the second factor consisted of six items $(\alpha=.87)$, and the third factor consisted of two items $(r=.67, p<.01)$. Table 5 presents the eigenvalues and total variance explained by these factors.

Table 5: Total Variance Explained by Three Extracted Factors of the Big Picture Appraisal Scale.

\begin{tabular}{lcccccc}
\hline Factor & \multicolumn{3}{c}{ Initial Eigenvalues } & \multicolumn{3}{c}{ Extracted Sum of Squares Loadings } \\
\cline { 2 - 7 } & Total & $\begin{array}{c}\text { Percent } \\
\text { Variance }\end{array}$ & $\begin{array}{c}\text { Cumulative } \\
\text { Percent }\end{array}$ & Total & $\begin{array}{c}\text { Percent } \\
\text { Variance }\end{array}$ & $\begin{array}{c}\text { Cumulative } \\
\text { Percent }\end{array}$ \\
\hline 1 & 9.67 & 42.05 & 42.05 & 9.18 & 39.90 & 39.90 \\
2 & 1.67 & 7.28 & 49.33 & 1.25 & 5.45 & 45.35 \\
3 & 1.25 & 5.45 & 54.78 & .855 & 3.72 & 49.06 \\
\hline
\end{tabular}


Figure 3: $\quad$ Scree Plot of Exploratory Factor Analysis for Additional Analysis of 23 Items for Big Picture Appraisal Questionnaire.

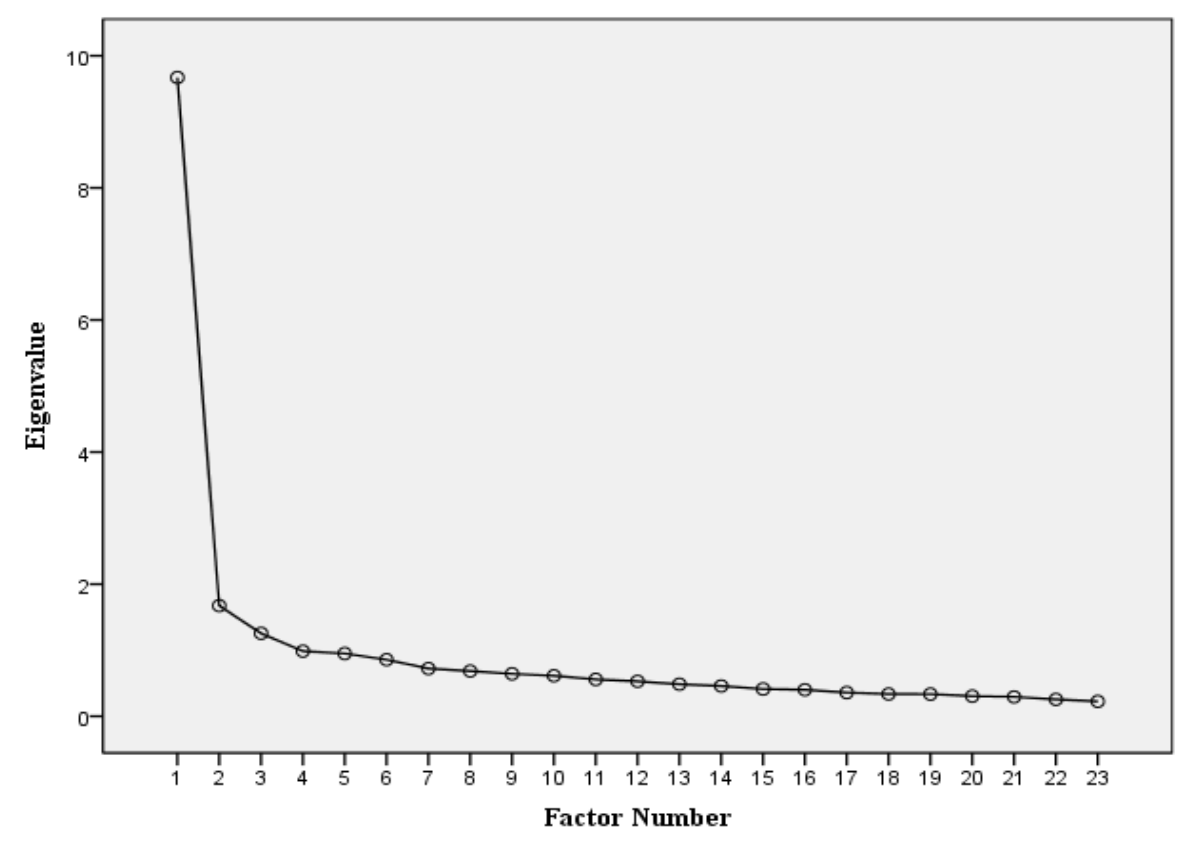

The first factor contained ten items, seven based on the growth and learning facet, one from the broader human context facet, and one based on the extended time perspective facet of big picture appraisal. The second factor consisted of six items, five of which were considered to measure the broader human context component of big picture appraisal and one that was written to assess acceptance. Finally, the third factor contained two items intended to measure the broader context of one's life. A table containing the retained factors and their corresponding items in Table 6. 
Table 6: $\quad$ Factor Loadings for Exploratory Factor Analysis with Promax Rotation and a Three-Factor Solution of the Big Picture Appraisal Questionnaire.

\begin{tabular}{|c|c|c|c|}
\hline \multirow{2}{*}{ Item } & \multicolumn{3}{|c|}{ Factor Loadings } \\
\hline & Factor 1 & Factor 2 & Factor 3 \\
\hline $\begin{array}{l}\text { I remember that other aspects of my life are } \\
\text { going better. }\end{array}$ & -.07 & .07 & .79 \\
\hline $\begin{array}{l}\text { I remind myself that I will grow from this } \\
\text { experience }\end{array}$ & .73 & -.13 & .15 \\
\hline $\begin{array}{l}\text { I know that other areas of my life are going } \\
\text { okay. }\end{array}$ & .06 & -.05 & .82 \\
\hline $\begin{array}{l}\text { I remind myself that painful experiences are a } \\
\text { part of everyone's life. }\end{array}$ & .41 & .23 & .08 \\
\hline $\begin{array}{l}\text { I know I will be able to come to terms with } \\
\text { this. }\end{array}$ & .54 & .02 & .05 \\
\hline $\begin{array}{l}\text { I reflect on how people I know have gone } \\
\text { through similar situations. }\end{array}$ & .15 & .37 & .05 \\
\hline I know this situation will teach me things. & .92 & -.18 & .02 \\
\hline $\begin{array}{l}\text { I understand that the situation will look } \\
\text { different to me after some time passes. }\end{array}$ & .57 & .05 & .01 \\
\hline I view this as a part of life's lessons. & .73 & .06 & -.05 \\
\hline I stay aware of what I can do well. & .27 & .13 & .35 \\
\hline I find inspiration in other people's experiences. & .22 & .29 & .16 \\
\hline it feels like I will be wiser from this. & .77 & -.01 & .01 \\
\hline $\begin{array}{l}\text { I remind myself that what I am experiencing is } \\
\text { something everyone feels. }\end{array}$ & -.09 & .67 & .13 \\
\hline I know there is value in painful experiences. & .59 & .23 & -.08 \\
\hline $\begin{array}{l}\text { I remind myself that I have felt this bad before } \\
\text { and come out of it. }\end{array}$ & .30 & .26 & .06 \\
\hline I know that this is only part of my life. & .46 & .24 & -.11 \\
\hline I realize that I will learn from this. & .86 & -.02 & -.07 \\
\hline $\begin{array}{l}\text { I am aware that other people often feel the way } \\
\text { that I do. }\end{array}$ & .07 & .69 & .04 \\
\hline I remind myself that suffering is part of life. & .22 & .60 & -.13 \\
\hline $\begin{array}{l}\text { I know there is value in experiencing my } \\
\text { emotions fully. }\end{array}$ & .31 & .44 & -.06 \\
\hline $\begin{array}{l}\text { I remind myself that everyone suffers } \\
\text { sometimes. }\end{array}$ & -.10 & .90 & -.01 \\
\hline
\end{tabular}


Table 6 Continued

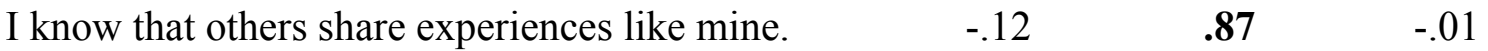

I know that there are many ways to view the $\quad \begin{array}{lll}.36 & .24\end{array}$

difficult situation.

Note. Factor loadings $>.40$ are in boldface.

The three factors were further explored by performing the validity and reliability tests used to examine the one-factor model above. Table 7 contains the correlations between the unit-weighted scores corresponding to each factor and participants' scores on the other measures given in Study 2. In general, these correlations are consistent with those found for the one-factor model. However, the correlations seen between the second and third factors and the other measures are smaller than those found for Factor 1 or for the single-factor model although the difference is probably not statistically significant. This may be in part due to the smaller number of items contained in the second and third factors and the resultant lower reliability. It may also be due, at least in part, to unique aspects of big picture appraisal that are represented through these factors, and thus differ slightly in their relationship to the other constructs measured. It is also worth noting that participants' scores on Factor 2 were not found to be significantly related to their scores on the MAAS. The lack of relationship between these items and the MAAS may help to provide some explanation as to unexpected findings between the BPAQ total scores and the MAAS noted above. 
Table 7: $\quad$ Correlations between Total Weighted Scores for Three-Factor Model of Big Picture Appraisal Questionnaire and Other Measures Given.

\begin{tabular}{lccc}
\hline \multicolumn{1}{c}{ Scale } & Factor 1 & Factor 2 & Factor 3 \\
\hline $\begin{array}{l}\text { Experiences Questionnaire (EQ) } \\
\text { Decentering Subscale }\end{array}$ & $.43^{* *}$ & $.36^{* *}$ & $.34^{* *}$ \\
$\begin{array}{l}\text { Cognitive Flexibility Inventory } \\
\text { (CFI) - Alternatives Subscale }\end{array}$ & $.39 * *$ & $.23^{* *}$ & $.19^{* *}$ \\
$\begin{array}{l}\text { Behavior Identification Form } \\
\text { (BIF) }\end{array}$ & $.25^{* *}$ & $.18^{* *}$ & $.14^{* *}$ \\
$\begin{array}{l}\text { Mindful Attention Awareness } \\
\text { Scale (MAAS) }\end{array}$ & $.18^{* *}$ & .07 & $.10^{*}$ \\
$\begin{array}{l}\text { Difficulties in Emotion } \\
\text { Regulation Questionnaire (DERS) }\end{array}$ & $-.32^{* *}$ & & \\
\hline Note. * $p<.05, * * p<.01$. & & & $-.16^{* *}$ \\
\end{tabular}

In addition to examining the construct validity of the three factors, the predictive validity and temporal stability of scores based on each of the factors were also assessed. Each of these analyses was parallel to those done previously. Participants' scores on Factor 1 and the SRRS were entered first, and were found to account for a significant amount of the variance in participants' scores on the short form CES-D, $R^{2}=.01, F(2$, $489)=3.47, p=.03$, though it should be noted that this effect is small, accounting for approximately one percent of the variance in CES-D scores. The addition of the interaction term between big picture appraisal and stressful life events was then added. Results were also significant, $\Delta R^{2}=.01, \Delta F(1,488)=5.13, p=.02$. This indicates that participants' scores on Factor 1 moderates the impact of life stressors on their scores on the short form CES-D. 
The predictive validity of Factors 2 and 3 was examined following the same steps. Results for Factor 2 showed no significant first order effect $\left(R^{2}=.00, F(2,489)=.17, p\right.$ $=.84$, or interaction effect $\left.\Delta R^{2}=.01, \Delta F(1,488)=2.28, p=.13\right)$. In contrast, results for Factor 3 were mixed. When scores for participants on Factor 3 and the SRRS were entered, they were found to account for a significant amount of the variance seen in scores on the short-form CES-D, $\left(R^{2}=.02, F(2,489)=.5 .64, p=.00\right)$. However, when the interaction term was added, it was not found to be significant $\left(\Delta R^{2}=.01, \Delta F(1,488)\right.$ $=3.53, p=.06)$. In summary, the findings for Factor 1 mirror the original Study 2 analyses quite closely whereas results for Factor 2 were fairly different, and those for Factor 3 were similar, showing significant first order effects and a nearly significant interaction.

Concerning test-retest reliability, all three factors were found to be temporally stable. The test-retest reliability of Factor 1, Factor 2, and Factor 3, respectively were as follows: $r=.71, p=.01 ; r=.64, p=.01$; and $, r=.53, p=.01$. The level of temporal stability found was largest for Factor 1 and smallest for Factor 3. This may be partially attributable to the fewer number of items contained in Factors 2 and 3. 


\section{General Discussion}

The purpose of the present studies was to develop and validate a self-report measure of big picture appraisal. Past research on big picture appraisal, and similar constructs, has found that engaging in this type of thought process can act as an effective emotion regulation strategy, often working to lessen the distress an individual may experience in relation to a negative event (Baum \& Rude, 2011; Rude, Mazzetti, Pal, \&

Stauble, 2011). A series of data collections was conducted, with initial efforts focusing on the generation of a pool of items thought to reflect the different facets of big picture appraisal. After the items were created, two separate studies were performed. In the first study, an EFA was completed to explore the structure of big picture appraisal and to select items for the self-report measure. In the second study, a CFA was performed to assess the validity of the single factor solution found in Study 1, as well as the test-retest reliability and the predictive validity of the measure. Both studies allowed for further exploration and understanding of the construct of big picture appraisal through examination of the convergent and discriminant validity of the measure.

Results of the EFA indicated a single-factor solution containing 23 items. The items were drawn from all of the proposed facets of big picture appraisal: an extended time perspective, the broader context of one's life, the broader human context, acceptance, and growth and learning. These findings provide support that each of these hypothesized dimensions contributes to the definition of big picture appraisal, and suggest that perhaps the different facets of big picture appraisal are so closely related that they comprise one unifying construct. 
In Study 2, a CFA was performed based on the one-factor model previously found to examine the accuracy of the model and the internal consistency of the measure. The model was found to be a poor fit for the data. This finding would seem to contradict the results of Study 1, which, based on Cronbach's alpha, appeared to indicate a high level of internal consistency for the measure. However, CFA is often viewed as a stronger indicator of internal consistency, and allows for examination of the relationship between items and the proposed factor(s). Poor model fit often occurs when too few factors were indicated during the exploratory factor analysis (Brown, 2006). Too few factors can be found as a result of issues such as items being worded similarly. When this occurs, the measurement errors of these items may be correlated. This means that variance in the items' scores is shared not only because of the underlying construct being measured, but also because of shared measurement error, which is not accounted for in the EFA.

An additional EFA was performed on the second data set to gain a greater understanding of the lack of fit. This analysis used an oblique rotation to find a threefactor model, with 18 of the 23 items meeting the criteria to be retained. These findings are consistent with the theory that big picture appraisal is a multifaceted construct, with the factors closely related to one another. Additionally, the three factors were examined for construct validity, predictive validity, and test-retest reliability. Overall, results were consistent indicated the three factors related to similar constructs in a manner consistent with the theory of big picture appraisal. Thus, taken together, these findings indicate that the lack of internal consistency may be the result of an inappropriate, single-factor model having been indicated during the first EFA. A model more consistent with the 
conceptualization of big picture appraisal, which includes multiple dimensions or subscales, may be a more accurate representation of the construct as reflected in a selfreport measure.

Construct validity was examined in both studies by comparing participants' scores on the BPAQ to measures of constructs that had been theorized to related to big picture appraisal. In Study 1, big picture appraisal was found to be positively related to selfcompassion, consistent with both constructs sharing similarities related to an individual's ability to see how his or her personal experiences relate to or are similar to what other people experience. Supporting the idea of big picture appraisal as a form of cognitive reappraisal, it was found to be related to the reappraisal subscale of the ERQ. The BPAQ was found to have a positive relationship with the openness subscale of the BFI, and a negative but relatively modest relationship with the neuroticism subscale, consistent with these being related but distinct constructs.

Neither rumination nor suppression was found to be related to big picture appraisal. A negative relationship between the BPAQ and the RRS had been hypothesized based on previous findings indicating that the use of big picture appraisal was associated with lower levels of rumination (Rude, Mazzetti, Pal, \& Stauble, 2011). Similarly, it was also hypothesized scores on the BPAQ would be negatively associated with scores on the ERQ-Suppression subscale. The lack of relationship found between the BPAQ and these measures may indicate that the use of big picture appraisal does not directly inhibit the use of these other thought processes. Instead it may be a separate appraisal process that can occur in conjunction with processes such as rumination and 
suppression. This finding may indicate that individuals are not avoiding their negative emotions by attempting to gain distance or perspective, but instead are using multiple strategies to manage their emotions. However, further research is needed to more fully understand how these constructs are related. It is possible that as a multifaceted model of big picture appraisal is explored, findings could indicate that certain dimensions of big picture appraisal relate to rumination and suppression in a unique manner.

In Study 2, scores on the BPAQ were compared to measures of decentering, cognitive flexibility, construal, difficulties with emotion regulation, and mindfulness. Decentering was found to be positively related to big picture appraisal, supporting the concept that big picture appraisal is related to the ability to step outside of one's experiences. An individual's ability to shift his or her perspective, defined as cognitive flexibility, was also found to be related to big picture appraisal. Additionally, big picture appraisal was shown to be related to a person's tendency to focus on the higher-level implications, such as motives, of his or her actions. Big picture appraisal was also found to be negatively related to difficulty regulating emotions, consistent with the view of big picture appraisal as an effective emotion regulation strategy. Big picture appraisal was not found to be significantly related to mindfulness, as assessed by participants' scores on the MAAS, despite a positive relationship having been hypothesized due to both constructs containing the concepts of awareness and openness in their definitions. This unexpected finding may be indicative of differences in how these constructs were assessed, with the MAAS incorporating multiple items focused on attentiveness and physical actions. For example, the MAAS contains items such as, "I forget a person's 
name almost as soon as I've been told it for the first time." This is in contrast with the proposed items measuring big picture appraisal, which primarily assess a range of thoughts and emotional experiences a person may have in relation to a distressing event.

Predictive validity of the proposed measure of big picture appraisal was assessed, with findings indicating that the relationship between participants' score on the measure of life stress at Time 1 with their scores on the CESD-short form at Time 2 was moderated by their use of big picture appraisal. When examined more closely, these findings revealed that increased use of big picture appraisal appears to be protective against depressive symptoms typically associated with a high level of life stress. However, the effect of this relationship was small, accounting for only one percent of the variance, and causality for this difference in scores cannot be assumed. Additionally, participants completed the short-form CES-D only once, at Time 2, meaning that any change in symptoms was not assessed. Therefore, the results are essentially a crosssectional analysis. It is possible that future research using participants with greater variance in distress and severity of depressive symptoms over a longer period of time might be expected to produce a larger moderation effect.

The temporal stability of the proposed measure was assessed and found to be adequate. This finding supports the assumption that the measure is assessing the same construct over time.

As a whole, the findings of both studies indicate that the BPAQ is temporally stable and measures a construct at least roughly consistent with theoretical accounts of big picture appraisal. Indirectly, these findings support the validity of the construct of big 
picture appraisal as seeing a distressing event as part of a larger whole. These results are also consistent with what has been found in research examining the related constructs of self-distancing, imagery perspective, and perspective broadening (Kross et al., 2005;

Libby et al., 2011; Shartau et al., 2009). Self-report measures have not yet been developed for these seemingly related constructs. Given the variations in these theories, such as perspective broadening proposing four facets to the theory, in contrast to selfdistancing and imagery perspective conceptualized as unitary constructs, the present results may provide additional insight (Kross et al., 2005; Libby et al., 2011; Shartau et al., 2009). These studies appear to provide support indicating that the ability to gain a larger perspective on an emotionally distressing event may be multifaceted.

However, the exploratory and confirmatory factor analyses yielded contradictory findings regarding the structure of proposed measure. Results of these studies indicate that conceptualizing the BPAQ as a single factor does not appear to adequately represent the measure; instead, the measure appears to be multidimensional, incorporating the concepts of growth and learning, an extended time perspective, the broader human context, and the broader context of one's life. This finding appears to be logical given the abstractness of the concept of considering the larger context for events and the very different ways this type of thinking can manifest. For example, keeping in mind that emotions have a natural ebb and flow, at least on the surface, seems quite different from being aware that one's experiences are typical 'human' experiences, shared with many others. It is not yet well understood whether these dimensions function in the same or a similar manner to one another. It is possible that certain facets of big picture appraisal 
are more effective at regulating emotions. For example, the preliminary results found regarding predictive validity indicates that the broader human context dimension may not be as effective at buffering an individual against the effects of stress in comparison to the dimensions of growth and learning, the extended time perspective, and the broader context of one's life. Of course, this result is only preliminary, and further research is needed to clarify the relationship between dimensions of big picture thinking and effective emotion regulation. Given that the first factor functions in a manner very similar to the single-factor model originally indicated, these results may also indicate that this ten-item scale constitutes an adequate measure of the construct. However, further research replicating this finding would be needed.

Findings across these subscales were consistent with what had been found for the single-factor model, however, there were slight variations in how they relate to other constructs. Specifically, while the first and third factors were found to be significantly related to mindfulness, consistent with prior predictions, the second factor was not. However, a small relationship was found in the predicted direction. The items composing this second factor mostly drawn from the broader human context items. It may be that a tendency to engage in this type of thinking draws individuals out of the present moment or in some other way acts in a manner that is inconsistent with mindfulness. It is also possible that this finding is at least in part the result of unique aspects of the MAAS as a measure of mindfulness. There is evidence that items on the MAAS may have difficulty discerning between levels of the trait (Van Dam, Earleywine, \& Borders, 2010). Additionally, while the MAAS currently is scored as a single factor, it originally was 
intended to contain two dimensions. Research indicates that a multifaceted measure of mindfulness may be a more accurate representation of the trait (Lau et al., 2006). Given these findings it is possible that the items contained in the BPAQ may assess aspects of mindfulness not fully assessed by the MAAS.

Despite the support found for the BPAQ in these two studies, a replicable structure was not established. Future research will need to build upon the information gathered here in order to define the structure of the construct and the formation of a wellsupported self-report measure. Next steps should include further examination of the three-factor structure found in the additional analysis. Given the results regarding construct validity and the consistency of these findings with the theory of big picture appraisal, it is reasonable to assume that this model may be a better fit for the self-report measure and the overall construct. Due to the third factor being composed of only two items, as well as indications on the scree plot indicating a possible two-factor solution, future research should include generating additional items that could be integrated into the measure and are consistent with those that have been retained. A larger EFA should then be performed, with additional measures such as those included in Study 1 given as well to continue establishing construct validity for the revised measure. Based on the results of these analyses, it may then be reasonable to follow with an additional study in order to perform a second CFA. By doing so, researchers would gain a greater understanding of the dimensions being measured by the items that compose the BPAQ. Multiple limitations impacted the findings of these studies. First, while there are many advantages to self-report measures, such as the fact that they are generally 
straightforward to interpret and practical to administer, there are also disadvantages associated with this type of measure. One limitation is that participants may not have been willing or able to give an accurate portrayal of their behaviors regarding their use of big picture appraisal. This can be caused by a number of factors. At times individuals want to answer self-report measures in a way that seems most desirable. While this study attempted to control for this through the administration of the social desirability scale, it is possible that participants still attempted to respond in a manner they viewed as more desirable. Additionally, at times participants may respond by either answering using only the extreme ends of the response scale or by answering without reading the items. While there was no indication in the present data that participants were consistently answering using only the extreme ends of the scale, it is possible that they responded randomly without carefully reading the items.

In addition to these challenges, participants were asked to respond to the big picture appraisal items based on past thoughts and behaviors, which they may not accurately remember. For many individuals, this type of thinking may be particularly hard to assess as it may happen automatically, without their conscious awareness. Conversely, it is possible that because many participants were likely responding to items when they are not emotionally distressed, they may overestimate the rate at which they engage in these types of thought processes. Relatedly, an individual's identity may become a factor. If they view themselves as someone who is able to engage in emotion regulation strategies such as big picture appraisal, they may be more likely to endorse items consistent with this view. If they view themselves as more volatile, they may 
answer negatively. These self-views may not be consistent with either how others see them or with how their use of big picture appraisal objectively occurs.

Despite these limitations, it has been argued that self-report measures are still the best method at assessing personal conceptions of the self (Kagan, 2005). When assessing internal experiences, individuals have access to the greatest quantity of information regarding their thoughts and emotions. These experiences may not always be visible to outside observers, and at times may even be contrary to what can be seen by others.

Beyond issues related to self-report measures, there are also limitations to these studies regarding the generalizability of the findings. Participants in both large data sets were undergraduate college students. It is not known if the relationships found here will remain the same across populations. Factors such as gender, age, level of education, and religion could impact whether individuals engage in big picture appraisal and how it compares for them to related constructs. For example, it may be that individuals who are members of more collectivist cultures are more inclined to use certain aspects of big picture appraisal, such as common human experiences, over others, which would shift the structure of the BPAQ. Once a well-supported structure for the BPAQ has been established, research will be needed to assess its applicability across populations.

Various potential benefits of a self-report measure of big picture appraisal exist. For example, as interventions are designed, such a measure would allow for the more accurate assessment of impact and outcomes. In addition, it could also allow for a more in-depth exploration of populations and situations that are more or less positively and negatively impacted by the use of big picture appraisal. It is possible that there are 
periods of time in which the use big picture appraisal could be viewed as invalidating, such as immediately following an emotionally distressing event, thus having a negative impact on mental health. It is also possible that depending on the type of event that the individual has experienced, such the death of a loved one, the use of big picture appraisal could contribute to feelings of loss or a sense of being overwhelmed. Determining these factors could provide important information with both theoretical and practical applications. 


\section{Appendices}

\section{Appendix A}

\section{LITERATURE REVIEW}

Big picture appraisal is conceptualized as a form of emotion regulation that has much in common with mindfulness. Hence, theories and research concerning emotion regulation, mindfulness, and their impact on mental health are addressed. The related constructs of self-compassion, self-distancing, imagery perspective, perspective broadening, and big picture appraisal will then be discussed. Last, the data from first steps in the creation of a self-report instrument measuring big picture appraisal will be presented.

\section{Emotion Regulation}

Researchers have explored different ways of conceptualizing how people try to regulate their emotions (for reviews see Aldoa et al., 2010; Gratz \& Roemer, 2004; Gross, 2007; Koole, 2009). While much is still unknown, two conceptualizations of emotion regulation, which share some similarities, have become more widely accepted within the field.

\section{Classification system of emotion regulation}

Koole (2009) defined emotion regulation as, "the set of processes whereby people seek to redirect the spontaneous flow of their emotions." One key component to understanding strategies that can be classified as types of emotion regulation is that the individual is using them in an attempt leave an emotional state. These processes may be deliberate and effortful, or they may be automatic and relatively effortless, meaning they 
may occur consciously or unconsciously. While a great deal of emphasis has been given to strategies used to regulate negative emotions, research shows that emotion regulation strategies are used to increase or decrease positive or negative emotions (Koole, 2009). It is important to note that individuals are not always successful in their efforts to make a specific change or series of changes concerning their emotions, meaning that their emotion regulation strategy may not always accomplish their goal state (Koole, 2009; Wegner, Erber, \& Zanakos, 1993).

There are a vast number of activities that can be classified as emotion regulation strategies as, hypothetically, any activity that impacts one's emotions would qualify (Koole, 2009). In one study, researchers performed an exploratory factor analysis in an effort to discern common themes within the more than 400 strategies that people reported engaging in; however, no replicable structure was ever produced (Skinner et al., 2003). In contrast with that approach, Koole (2009) posited a dual classification system based on the target and the function of the emotion regulation strategy. The targets of emotion regulation include attention, emotion-relevant knowledge, and bodily emotion responses. Strategies are then classified within these three target categories based on which of three functions (need-oriented, goal-oriented, or person-oriented) they serve.

Taking a closer look at how the classification system works, meditation is a process has been explored as an effective emotion regulation strategy (Cahn \& Polich, 2006). According to the proposed system, meditation would be classified as targeting attention and person-oriented in focus (Koole, 2009). Stress-induced eating, which has also been found to be an emotion regulation strategy, would be classified as targeting the 
body and need-oriented in focus (Greene \& Wing, 1994; Koole, 2009). However, Koole (2009) acknowledges that it can be difficult to fit strategies into this system, as a given strategy may fit into multiple categories. These issues exemplify the difficulties that face researchers as they balance the need for an overall framework for understanding emotion regulation with the need for more nuanced understandings of various emotion regulation strategies.

\section{The process model of emotion regulation}

One of the dominant theories of emotion regulation is the process model proposed by Gross (1998b). According to this theory, emotion regulation can be defined as "the processes by which individuals influence which emotions they have, when they have them, and how they experience and express these emotions" (Gross, 1998b). Gross' theory also incorporates the idea that emotion regulation processes or strategies may be deliberate or conscious, or they may happen in a more automatic or unconscious manner. Additionally, it includes that emotion regulation processes can be focused on increasing or decreasing both positive and negative emotions (Gross, 2007). This interpretation of emotion regulation is used as the foundation for the rest of the model.

Gross proposed two levels of classification of emotion regulation in the process model (1998b). First, five different types of emotion regulatory processes were identified. Four of these types of emotion regulation processes are classified as antecedent-focused emotion regulation, and the last type is classified as response-focused emotion regulation (Gross, 1998a,b; Gross \& John, 2003). More specifically, situation selection, situation modification, attention deployment, and cognitive change are all 
considered to be antecedent-focused, meaning that individuals engage in these emotion regulation strategies before their emotions are fully activated. Response modulation is considered to be response-focused, meaning that emotion regulation processes that fall into this category occur after the individual's emotions have been fully activated and his or her response to the emotion is underway (Gross, 1998b).

Of the five different categories of processes proposed by Gross, one form of cognitive change, reappraisal, and one form of response modulation, suppression, have both been studied extensively (Aldoa et al., 2010; Gross, 1998a; Gross, 2002; Gross \& John, 2003). Reappraisal has been defined as a cognitive change in which the individual adjusts how he or she is thinking about a situation in order to change or prevent an emotional reaction (Gross, 2002; Gross \& John, 2003; Lazarus \& Alfert, 1964). For example, if a student is assigned a book to read, they might choose to view it as a learning opportunity instead of as an unwanted burden. Theoretically, by changing his or her view of the assignment, the student is able to change the emotional reaction before it fully begins. Research indicates that when people are able to engage in this type of emotion regulation process they are not only changing how they react to a situation behaviorally, but they also are changing what they experience internally (Gross \& John, 2003; Gross \& Thompson, 2007; Lowenstein, 2007).

The use of suppression as an emotion regulation process has also been researched at length, often in conjunction with reappraisal. It has been defined as an individual inhibiting his or her emotion-expressive behavior, meaning that an effort is made to stop or prevent a behavior that would be consistent with the emotion being experienced 
(Gross, 1998a). Suppression falls into the category of response modulation, thus indicating that it is a strategy that is used later in the process of emotion regulation (Gross, 1998b). Suppression is thought to largely modify the behavior one engages in when reacting to an emotional cue. This means that while suppression is effective in decreasing the behavioral expression of a negative emotion, it does not keep the individual from experiencing the negative emotion (Gross, 2002). Additionally, unlike reappraisal, it has also been found to decrease both the expression and the experience of positive emotion (Gross, 2002; Gross \& John; 2003).

\section{Emotion regulation and mental health}

Evidence has indicated that specific emotion regulation strategies are often associated with mental health issues such as depression and anxiety, and other emotion regulation strategies are associated with improved mental health (Aldoa et al., 2010). Three emotion regulation strategies that have been linked to the development of psychopathology are suppression, avoidance, and rumination (Aldoa et al., 2010). Individuals who engage in higher rates of suppression have reported experiencing more negative emotions compared to people who suppress less often. They also report experiencing feelings of being inauthentic and of misleading others about who they are (Gross \& John, 2003). Additionally, research indicates that when individuals try to suppress their thoughts it leads to increases in emotional arousal (Gross \& John, 2003; Wegner, Broome, \& Blumberg, 1997). When information across studies is collapsed, suppression has been found to have a significant relationship with increased 
psychopathology, particularly with internalizing disorders such as depression and anxiety (Aldoa et al., 2010).

Similarly, the use of avoidance, which has been defined as evading psychological experiences, has been linked to a range of anxiety disorders, as well as to substance abuse and binge eating (Aldoa et al., 20101; Hayes, Strosahl, \& Wilson, 1999; Lissek et al., 2009; Merckelbach, de John, Muris, \& van den Hout, 1996; Polivy \& Herman, 2002). In contrast with avoidance, some individuals use rumination, which is the practice of repeatedly focusing on their emotional experiences, as a form of emotion regulation (Nolen-Hoeksema, Wisco, \& Lyubomirsky, 2008). While people have indicated that they ruminate in an effort to help themselves understand and solve their problems, research has shown that rumination actually interferes with problem solving (Hong, 2007; Ward, Lyubomisky, Sousa, \& Nolen-Hoeksema, 2003). Rumination has also been found to have a strong relationship with the development of psychopathology, particularly depression and anxiety, and, to a lesser extent, eating disorders and substance abuse (Aldoa et al., 2010)

In contrast with the findings concerning suppression, rumination, and avoidance, many emotion regulation strategies including reappraisal, problem solving, and acceptance are thought to be protective against the development of psychopathology (Aldoa et al., 2010). As stated above, reappraisal has been defined as an individual shifting his or her thoughts concerning a situation or event in order to change their emotional experience (Gross, 2002; Gross \& John, 2003; Lazarus \& Alfert, 1964) Reappraisal has been associated with different outcomes such as experiencing and 
expressing fewer negative emotions and more positive emotions, being more likely to share emotions with others, and being more well-liked by others when compared to people who do not engage in reappraisal often (Gross \& John, 2003; Lowenstein, 2007). Individuals who are more inclined to engage in reappraisal have also been found to experience lower levels of depression, lower levels of anxiety, better self-esteem, and higher life satisfaction (Aldoa, et al., 2010; Gross \& John, 2003).

Problem solving is a strategy that has been incorporated into treatments such as Cognitive Behavioral Therapy. It has been found to have a positive effect on mental health, with research indicating that it is associated with lower levels of psychopathology (Aldoa et al., 2010; Beck, Rush, Shaw, \& Emery, 1979). Support for the impact of acceptance as an emotion regulation strategy has been found a few different ways. It has been argued that the research linking avoidance with increased psychopathology provides support for acceptance as a positive emotion regulation strategy as avoidance can be viewed as the opposite of acceptance (Aldoa et al., 2010). In addition to this, acceptance has also been viewed as a component of other psychological constructs, such as mindfulness (Hill \& Updegraff, 2011).

Researchers have started to explore whether cultural differences may impact the mental health outcomes associated with the use of specific emotion regulation strategies. A recent meta-analysis by $\mathrm{Hu}$, Zhang, and Wang (2014) examined 48 studies that looked at the use of cognitive reappraisal and expressive suppression in either Western culture, defined as studies originating in European and North American countries, and Eastern culture, defined as studies originating in Asian countries. All included studies were 
published in English or Chinese. Concerning cognitive reappraisal, they found that there were no significant differences between cultures, with both Eastern and Western cultures finding that cognitive reappraisal is associated with increased positive and decreased negative mental health outcomes. Cultural values were found to be a significant moderator when examining expressive suppression. Across studies it was found that expressive suppression was negatively associated with indicators used to measure positive mental health outcomes. However, expressive suppression was not found to be significantly correlated with mental health outcomes, positive or negative, in Eastern cultures. These findings indicate the need for further research in understanding the impact of various emotion regulation strategies on mental health.

Mindfulness. Mindfulness is an emotion regulation strategy that researchers have begun to explore in more recent decades (Bishop et al., 2004). The current psychological concept of mindfulness can trace its foundation to meditation techniques used by Buddhist monks and lay people beginning more than 2,500 years ago (Kumar, Feldman, \& Hayes, 2008). It has been incorporated into a variety of mental health treatments targeted at psychopathologies including depression, anxiety, and borderline personality disorder (Brown \& Ryan, 2003; Hayes, et al., 1999; Kabat-Zinn, 1982; Linehan, 1993; Teasdale, Segal, Williams, Ridgeway, Soulsby, \& Lau, 2000).

Despite the high level of interest and work around the concept of mindfulness, it is a construct that has been difficult for researchers to define consistently across studies (Bishop et al., 2004; Van Dam, Earleywine, \& Borders, 2010). In an effort to move the scientific exploration of mindfulness forward, a group of researchers defined mindfulness 
as follows: "The first component involves the self-regulation of attention so that it is maintained on immediate experience, thereby allowing for increased recognition of mental events in the present moment. The second component involves adopting a particular orientation toward one's experiences in the present moment, an orientation that is characterized by curiosity, openness, and acceptance" (Bishop et al., 2004). This definition emphasizes the importance of attention or awareness when dealing with emotions, as well as the importance of openness and acceptance, two concepts that have been found to be important in emotion regulation (Bishop et al., 2004; Brown \& Ryan, 2003; Gratz \& Roemer, 2004; Hill \& Updegraff, 2011).

What does it mean to be aware of one's feelings? In the context of mindfulness, being aware indicates that one is observing and paying attention to his or her thoughts, feelings, and physical sensations in the present moment (Bishop et al., 2004). There are multiple theorized benefits of this kind of awareness or attention to the present moment. For example, if the individual is focused on the present moment he or she is able to notice the emotion being experienced. Additionally, this awareness keeps the individual from being able to engage in cognitive processes that would cause them to elaborate on the emotion in a negative manner (Bishop et al., 2004; Brown \& Ryan, 2003; Desrosiers et al., 2013). One example of this type of thought process is rumination, during which the individual continually revisits a past negative emotional experience (Nolen-Hoeksema et al., 2008). Research indicates that when individuals ruminate about a negative past event, or worry about future negative events or consequences, it can contribute to negative mental health outcomes including increased symptoms of depression and 
anxiety (Aldoa et al., 2010; Bishop et al., 2004; Desrosiers et al., 2013). In addition to helping disrupt rumination and worry, awareness of the present is thought to help prevent the individual from engaging in emotion regulation strategies such as avoidance, which has also been linked to increases in symptoms of depression and anxiety (Aldoa et al., 2010; Brown \& Ryan, 2003).

More generally, when individuals are able to mindfully engage with their emotions the increased awareness of what they are experiencing in the present can help them disengage from any automatic thoughts, habits, or unhealthy behaviors they have been using (Brown \& Ryan, 2003). The individual is then more capable of identifying his or her needs and desires, and they are better at identifying their emotions. When individuals are able to identify their needs and differentiate more effectively between their emotions, they show improvements in emotion regulation, they are then better able to get their needs met, and they experience less emotional lability (Brown \& Ryan, 2003; Hodgkins \& Knee, 2002; Hill \& Updegraff, 2011).

The concept of mindfulness goes beyond awareness of emotion and incorporates a component of curiosity and acceptance for one's thoughts, experiences, and emotions (Bishop et al., 2004). Researchers have theorized that by having an accepting and nonjudgmental attitude towards one's experiences, individuals are able to experience unpleasant thoughts and emotions with less emotional distress because they have changed the meaning of the emotions (Bishop et al., 2004; Hayes, et al., 1999). As was true for the awareness component of mindfulness, non-judgmental acceptance may help the individual to engage in fewer avoidant cognitive and behavioral strategies when dealing 
with emotions, and allow them to engage in behaviors that are considered to be more psychologically adaptive (Bishop et al., 2004; Desrosiers et al., 2013; Neff, 2003).

The third component of mindfulness that has been emphasized in treatment protocols is decentering (Hayes et al., 1999; Linehan, 1993; Teasdale et al., 2000). Decentering encourages the individual to try to remove themselves or distance themselves from the content of their thoughts and feelings and act as an outside observer (Hayes, Follete, \& Linehan; 2011). It is thought that by providing individuals with a way to gain greater perspective on their emotional experiences, in conjunction with awareness and acceptance, they are better able to tolerate their painful emotions and thoughts. This also makes it less likely that individuals will over-identify with their emotional experience and engage in emotion regulation strategies such as rumination and avoidance (Hayes, et al., 1999; Neff, 2003)

Mindfulness has been incorporated into a number of psychological interventions, which have been found to be effective in the treatment of a variety of mental health issues (Bishop et al., 2004; Brown \& Ryan, 2003; Desrosiers et al., 2013). Linehan's Dialectic Behavior Therapy is used in the treatment of borderline personality disorder. Research indicates that it can be effective in reducing self-harm behaviors and emotional lability in patients with the disorder who experience chronic suicidal ideation (Linehan, 1993). Mindfulness-based stress reduction (MBSR) has been found to reduce distress in a variety of settings including chronic pain and oncology treatment centers (Carlson, Speca, Patel, \& Goodey, 2004; Kabat-Zinn, Lipworth, \& Burney, 1985). Additionally, 
mindfulness-based cognitive therapy (MBBPT) has been found to reduce the rate of relapse in recurrent major depression (Teasdale et al., 2000).

In addition to researching its applications in clinical interventions, researchers have also started to use experimental designs to explore the effects of mindfulness as an emotion regulation strategy (see Keng, Smoski, and Robins, 2011 for review). One study found that when a dysphoric mood was induced, participants who were guided through a mindful meditation showed lower levels of negative mood compared to participants who were guided to use rumination or distraction (Broderick, 2011). Huffziger \& Kuehner (2008) had similar findings when they examined the use of distraction, mindful selffocus, or rumination as a way of coping with negative mood in participants who had previously been depressed. Participants who used either distraction or mindfulness were found to have a better mood than participants who had been induced to use rumination (Huffziger \& Kuehner, 2008). Researchers have also compared the use of suppression to the use of acceptance, a component of mindfulness, when either a high level of anxiety or a depressed mood has been induced (Campbell-Sills, Barlow, Brown, \& Hofmann, 2006; Levitt, Brown, Orsillo, \& Barlow, 2004). Participants in the acceptance group showed lower levels of anxiety based on subjective measures, though they did not show lower levels of anxiety based on physiological measures when compared to participants who used suppression (Levitt et al., 2004). When a depressed mood was induced, participants who used acceptance appeared to recover more quickly and showed lower heart rates compared with participants who used suppression (Campbell-Sills et al., 2006). 
These findings provide support for the idea that mindfulness encourages individuals to engage in more productive or beneficial emotion regulation strategies as compared to strategies such as rumination and suppression, which, as was noted above, have been correlated with increases in negative mental health outcomes such as depression and anxiety (Aldoa, 2010; Bishop et al., 2004; Desrosiers et al., 2013; Kumar, Feldman, \& Hayes, 2008). Researchers have begun to parcel out the pathways through which mindfulness may uniquely operate in individuals experiencing depression versus anxiety. Findings indicate that mindfulness may impact depression by decreasing an individual's ability to engage in rumination and increase his or her ability to engage in reappraisal, while individuals experiencing anxiety it may be impacted by experiencing a decrease in worry (Desrosiers et al., 2013). However, a great deal is still unknown concerning how the components of mindfulness relate to one another and how they each contribute to the mental health outcomes individuals have experienced in association with mindfulness. This is particularly relevant given that specific aspects of mindfulness have been incorporated into theories such as self-compassion and appear to be related to other constructs being explored as possible emotion regulation strategies.

Self-Compassion. Self-compassion is an emotion regulation strategy that, like mindfulness, is based in Buddhist tradition, though in comparison to mindfulness, researchers have only recently become interested in it (Barnard \& Curry, 2011; Neff, 2003). Neff (2003) defined self-compassion as "being touched by and open to one's own suffering, not avoiding or disconnecting from it, generating the desire to alleviate one's suffering, and to heal oneself with kindness." Deconstructing this definition further, Neff 
(2003) proposed that self-compassion is composed of three facets. The first facet is selfkindness, which includes showing kindness and understanding towards oneself as opposed to engaging in self-judgment and self-criticism. Common humanity is the second facet, and involves an individual being able to see his or her experiences as part of the larger human experience. The final component of self-compassion is mindfulness, which Neff (2003) has defined as an individual being able to experience his or her painful thoughts and feelings with a balanced awareness, as opposed to over-identifying with them. It is thought that while each of the facets of self-compassion is distinct, they also interact in such a way that they are able to enhance one another (Neff, 2003).

Researchers have begun to explore the impact that the use of self-compassion has on mental health. Neff, Rude, \& Kirkpatrick (2007) found that self-compassion is associated with higher levels of happiness, optimism, positive affect, wisdom, personal initiative, curiosity and exploration, agreeableness, extroversion, and conscientiousness. Additionally, researchers have found that self-compassion was positively correlated with positive affect and negatively correlated with negative affect (Leary, Tate, Adams, Batts, \& Hancock, 2007; Neff, Kirkpatrick, \& Rude, 2007; Neff \& Vonk, 2009). In conjunction with these findings, self-compassion has been found to be associated with lower levels of depression and anxiety, as well as increased feelings of well-being and life satisfaction (Neely, Schallert, Mohammed, Roberts, \& Chen, 2009; Neff et al., 2007; Raes, 2010). Self-compassion has also been studied in comparison to other emotion regulation strategies, and findings indicate it is negatively correlated with the use of rumination, suppression, and avoidance strategies (Neff, 2003; Neff et al., 2007; Neff \& Vonk, 2009; 
Raes, 2010). This body of research provides strong support for the possible positive impact self-compassion may have on mental health. Additionally, as was true for mindfulness, these findings also provide impetus for researchers to more fully understand each of the facets of self-compassion, both in how they relate to similar constructs and their impact on mental health.

Self-Distancing. The research discussed above indicates that being aware or cognizant of one's own emotional state has generally been found to have a positive impact on mental health outcomes (Bishop et al., 2004; Hayes, et al., 1999). However, one question that researchers have struggled with is whether it is helpful for people to reflect on their emotional experiences, as many of the findings appear to be contradictory. Rumination is considered to be one version of such reflection, and it has been associated with negative mental health outcomes (Aldoa et al., 2010; Nolen-Hoeksema, 2008). However, other findings indicate that people experience emotional and physical health benefits when they reflect on their feelings (Pennebaker, 2007). In order to try to gain a better understanding of these seemingly paradoxical findings, a group of researchers has begun to explore an emotion regulation strategy that they have termed self-distancing (Ayduk \& Kross, 2010; Kross, Ayduk, \& Mischel, 2005; Kross \& Ayduk, 2008; Kross \& Ayduk, 2011).

Self-distancing or having a self-distanced perspective on a situation has been described as the individual being able to view an event that evokes sadness or anger as if they are a fly on the wall. In some ways this is a similar concept to the idea of decentering (Ayduk \& Kross, 2010; Hayes et al, 2011). This is contrasted with the idea 
of a self-immersed perspective, which is conceptualized as the individual remembering the event from his or her own perspective (Ayduk \& Kross, 2010). It is theorized that when individuals use a self-immersed perspective they are more likely to take a narrow view of the situation and focus more on the concrete details of what occurred.

Conversely, it is thought that when individuals are able to use a self-distanced perspective they are better able to take the big picture into account. This allows them to reconstrue the experience in a way that lessens the distress they experience due to the situation or event (Kross \& Ayduk, 2011).

A number of studies have been completed that indicate that self-distancing can have an effect on the emotions that people experience around negative events. Multiple studies found that when participants were asked to reflect on a negative event that evoked either sadness or anger, participants who used a self-distanced perspective experienced less distress immediately following the exercise in comparison to participants who use a self-immersed perspective (Kross \& Ayduk, 2008; Kross et al., 2005). Additionally, when asked to think about the same experience up to one week later, participants who used a self-distanced perspective were found to be experiencing less emotional distress and to be ruminating less compared to participants who had used a self-immersed perspective (Kross \& Ayduk, 2008).

When self-distancing was compared to the use of distraction as an emotion regulation strategy, findings indicated that initially both strategies were equally effective at reducing distress. However, at a one-week follow up, participants who used selfdistancing to reflect on their experience again reported that they were ruminating less 
about their experience and that they became less distressed when thinking about the experience compared to the group that had used distraction (Kross \& Ayduk, 2008). Findings also indicated that both participants who were prompted to use self-distancing and those who did it spontaneously were less physically reactive when reflecting on their emotions, providing further evidence for the beneficial effects of this type of thinking (Ayduk \& Kross, 2010).

Given the implications of these findings, researchers have begun to explore the use of self-distancing as an emotion regulation strategy with individuals who have been diagnosed with major depressive disorder (Kross, Gard, Deldin, Clifton, \& Ayduk, 2012). The positive outcomes associated with using a self-distanced perspective when analyzing a negative life experience appear to hold true both for individuals who are experiencing depression and for those who are not. Researchers found that when individuals were able to use a self-distanced perspective they were able to focus less on the negative feelings associated with an event and they were better able to shift their perspective to a more adaptive view (Kross et al., 2012). Given that rumination can at times be misinterpreted as a useful type of self-reflection, these findings are of particular importance given the strong relationship between rumination and depression that has previously been found in research (Aldoa et al., 2010; Nolen-Hoeksema, 2008).

Recently, researchers have begun to explore self-distancing not just in relation to negative emotions but also in relation to positive emotions in order to try to gain a more nuanced understanding of this emotion regulation strategy (Verduyn et al., 2012). In a series of studies, researchers found that when individuals used a self-distanced 
perspective when processing both positive and negative events, they experienced their emotions for a shorter period of time when compared to instances when they used a selfimmersed perspective (Verduyn et al., 2012). These findings have important implications concerning how an individual might use of self-distancing to the greatest effect.

Additionally, they also exemplify the importance of gaining more nuanced understandings of the impact that emotion regulation strategies can have on an individual.

Imagery Perspective. Researchers have investigated the use of imagery perspective as an emotion regulation strategy. In these studies, instead of using a selfdistanced or self-immersed perspective to process a specific emotional event, individuals are prompted to use either their own first-person perspective or to use a third-person perspective (Libby et al., 2011; Valenti, et al., 2011). Using the first-person perspective, the individual focuses on the concrete features of the negative event, such as the physical sensations and the emotions associated with the event. In contrast with this, using a third-person perspective prompts the individual to connect the event to his or her larger goals or to see other aspects of his or her life or self (Libby et al., 2011; Valenti, et al., 2011). While prior research appeared to support the idea that the use of a third-person perspective was beneficial for people processing negative events, these researchers theorized that those effects might vary based both on individual differences and on the type of event being processed (Libby et al., 2011; Valenti et al., 2011).

In order to test this theory, a series of studies was performed examining the impact of whether the individual had low or high self-esteem and whether the event they recalled involved action or inaction (Libby et al., 2011). Specifically, participants were 
asked to recall a time when they regretted an action they took or to recall a time when they regretted not acting. The results indicated that when individuals focused on a situation in which they did not act, all participants experienced more regret when using the third-person perspective as compared to when they used a first-person perspective (Libby et al., 2011; Valenti et al., 2011). These results are consistent with the researchers' theory, as events focused on inaction appear to be less painful when recalled in concrete detail; however, participants experienced more regret when they thought about the impact not taking action might have had on the broader scope of their lives (Libby et al., 2011; Valenti et al., 2011). When participants were asked to recall situations in which they regretted an action taken, the outcomes varied based on the individual's level of self-esteem. Individuals with low self-esteem were found to experience more distress when using a third-person perspective, which was thought to be caused by these individuals overgeneralizing their failure. In contrast, individuals with high self-esteem experienced less distress when they used a third-person perspective to process an action they regretted (Libby et al., 2011; Valenti et al., 2011).

Perspective Broadening. Perspective broadening is an emotion regulations strategy that has only recently been explored, but it appears to be conceptually similar to the common humanity facet of self-compassion, mindfulness, self-distancing, and imagery perspective. Building on research in which participants' ways of processing emotional information is altered using a technique called cognitive bias modification (CBM), Shartau, Dalgleish, \& Dunn (2009) completed a series of studies that examined the effects of participants using the appraisal theme of perspective broadening. 
In this series of studies, the term perspective broadening was used to describe a theme that participants used to take a big picture view when presented with emotionally stimulating material (Schartau, et al., 2009). It was hypothesized that this big picture perspective would allow individuals to incorporate positive or adaptive information into their appraisal of the emotional information. Four themes were hypothesized as being a type of perspective broadening:

1. Every cloud has a silver lining: there are parts of a negative experience that may not be negative

2. Broader perspective: even if a certain experience is negative, there are other aspects of life that are positive

3. Time heals: once this negative event has passed, things will be better

4. Bad things happen: negative events are inevitable in life (Shartau et al., 2009).

The first three studies performed found that when participants were taught to appraise situations using perspective broadening, they reported decreases in emotional reactivity when presented with negative emotional stimuli. The final study found that participants who used perspective broadening to appraise an autobiographical memory showed a decrease in maladaptive processing of the memories.

This series of studies by Shartau et al. (2009) indicated that individuals benefit from being able to engage in perspective broadening when they are dealing with negative emotions. This was shown both through a decrease in self-reported emotions, as well as decreases in physiological measures of emotional reactivity. As lower emotional reactivity has been tied to better emotion regulation, these early findings provide some 
indication that this is an effective form of emotion regulation (Gratz \& Roemer, 2004; Shartau et al., 2009).

Big Picture Appraisal. Big picture appraisal has been defined as a way of thinking about a negative or distressing event in which the individual is able to develop a wider perspective. This wider perspective incorporates the larger situation and the larger time perspective for the given emotional event (Rude, 2011). As can be seen from this definition, big picture appraisal is a type of cognitive reappraisal as it encourages the individual to shift how he or she is thinking about an experience. It also draws from the concept of mindfulness as it emphasizes the importance of a particular type of awareness as one reflects on difficult events and emotions (Bishop et al., 2004; Rude, 2011). Akin to the common humanity aspect of self-compassion, it is thought to include a component that incorporates an individual's awareness of how his or her needs and experiences are similar to the needs and experiences of other people (Neff, 2003; Rude, 2011). Additionally, big picture appraisal appears to be similar to what has been proposed in the concepts of self-distancing, imagery perspective, and perspective broadening (Kross et al., 2005; Libby et al., 2011; Rude, 2011; Shartau et al., 2009).

It has been theorized that big picture appraisal incorporates three different categories of thought processes (Rude, 2011). The first category has been labeled "An extended time perspective" and includes thoughts that incorporate an awareness that emotions change with time, and that generally as one gets more temporal distance from a negative event his or her distress lessens. "The broader context of one's life" is the second category of thoughts that would fit under big picture appraisal. This category 
indicates the use of an awareness or perspective that one's life includes both positive and negative experiences. Lastly, "The broader human context" indicates the use of a perspective incorporating the ideas that every person in the world faces adversity and distress, and that the wants, needs, and goals of all humans are all fundamentally the same (Rude, 2011).

Researchers have begun to take a closer look at the use of big picture appraisal and the impact that it has on mental health, particularly in relation to emotion regulation. In one study, participants were asked to write about a recent rejection experience using contextual questions or analytical questions. Approximately one week after the writing task, participants who were given the big picture appraisal questions indicated they were experiencing lower levels of rumination and depressive symptoms when compared to participants who wrote responding to the analytical questions and when compared to a no writing control group (Rude, Mazzetti, Pal, \& Stauble, 2011). In addition to this, a second study found evidence that when big picture appraisal instructions were added to general expressive writing instructions, participants again showed lower depressive symptoms compared to a control group (Baum \& Rude, 2011).

More recently, research has been undertaken to see if it is possible to use more implicit strategies to explore whether individuals can be taught to use big picture appraisal and what if any impact it has on their thinking (Miller and Rude, 2013). For this study, participants were given a CBM task similar to the one used by Shartau et al. (2009). Participants were assigned to complete tasks based on one of two series of vignettes that either implicitly trained them to think in a manner consistent with big 
picture appraisal or in a manner consistent with evaluative thinking. Following a stressor task, the individuals who were in the big picture appraisal group were found to have a less negative mood in comparison to individuals in the evaluative group, indicating that the trainings were successful (Miller \& Rude, 2013). Based on the findings of these studies, big picture appraisal appears to benefit individuals when they are reflecting on an emotionally distressing event.

The concepts of mindfulness, self-compassion, self-distancing, imagery perspective, perspective building, and big picture appraisal all emphasize the importance of an individual being aware of a larger perspective when they process emotional events. Research into these constructs indicates that when used as emotion regulation strategies, these thought processes have a direct impact on the emotional experiences and mental health of the individual (Bishop et al., 2004; Kross et al., 2005; Libby et al., 2011; Neff, 2003; Rude, 2011; Shartau et al., 2009). Self-distancing, imagery perspective, perspective building, and big picture appraisal appear to be particularly close in relation to one another. While a significant amount of research has begun to look at each of these concepts in relation to emotion regulation and mental health, this body of research also shows that there is still a great deal that remains unknown. More specifically, while the presence of common characteristics provides support for each of these concepts, they also provide further impetus for clarification among the constructs. Additionally, research into these concepts is limited due to a lack of valid and reliable measures that can be used to gain a further understanding of the impact of these emotion regulation strategies on individuals. 


\section{Appendix B}

Original Directions and Pool of Items Proposed to Measure Big Picture Appraisal

\section{Directions:}

Please think back to times when you have felt upset or unhappy. Many different situations provoke such feelings (e.g., when you felt you had failed or did not live up to your own or others' expectations, or when you experienced a loss, or felt rejected), and the emotions involved may vary (e.g., hurt, anger, sadness, grief, jealousy). Rate each of the following items on a scale from 1 to 5 to indicate how often you have thoughts similar to those listed.

Response Scale:

\begin{tabular}{|c|c|c|c|c|}
\hline 1--- & $--2-----$ & ----3---------. & -4------------ & ----5 \\
\hline Never & Rarely & Sometimes & Frequently & Very \\
\hline
\end{tabular}

\section{Stem:}

When I am upset or unhappy...

1. I remind myself that if I wait it out I will eventually feel better.

2. I remember that other aspects of my life are going better.

3. I see myself as disconnected from other people.

4. I do not trust that I will ever feel better.

5. Sometimes I just get upset for a little while.

6. I remind myself that suffering is part of life.

7. I notice a negative pattern of behavior in my life.

8. I reflect on how people I know have gone through similar situations.

9. I know that my perspective is going to change with time.

10. I assume that I will be dealing with the negative effects of this for a long time.

11. I am aware that other people often feel the way that I do.

12. It seems like I am failing at everything.

13. I find inspiration in other people's experiences.

14. I view my problems as being worse than those of others.

15. I allow myself to feel my feelings.

16. I know that other areas of my life are going okay.

17. I assume that the strong emotions will never end.

18. I keep some awareness of the good parts of my life.

19. I know that there are many ways to view the difficult situation.

20. I lose perspective about better times.

21. I understand that the situation will look different to me after some time passes.

22. I view my situation as worse than that of other people. 
23. I view every part of my life negatively.

24. I remind myself that what I am experiencing is something everyone feels.

25 . I stay aware of what I can do well.

26. I forget that I do not always feel this bad.

27. I know that if I let myself feel things too much, I might get overwhelmed.

28. I keep in mind that feelings change.

29. I see myself as cut off from others.

30. I know there is value in experiencing my emotions deeply.

31 . I remind myself that everyone suffers sometimes.

32. I do not feel connected to others.

33. I know this is only part of who I am.

34. I don't let myself spend much time experiencing negative feelings.

35. I know that others share experiences similar to mine.

36. It seems okay to feel what I am feeling at the time.

37. I feel as if I am somehow separated from people.

38. I know that this is only part of my life.

39. I lose my ability to think about positive things that may be happening.

40. I remind myself that I have felt this bad before and come out of it. 


\section{Appendix C}

Big Picture Appraisal Questionnaire Items Used for Exploratory Factor Analysis

\section{Directions:}

Please think back to times when you have felt upset or unhappy. Many different situations provoke such feelings (e.g., when you felt you had failed or did not live up to your own or others' expectations, or when you experienced a loss, or felt rejected), and the emotions involved may vary (e.g., hurt, anger, sadness, grief, jealousy). Rate each of the following items on a scale from 1 to 5 to indicate how often you have had thoughts similar to those listed.

\section{Response Scale:}

\begin{tabular}{|c|c|c|c|c|}
\hline \multicolumn{5}{|c|}{ 1-------------------2--------------------3---------------------4--------------------5 } \\
\hline Never & Rarely & Sometimes & Frequently & $\begin{array}{l}\text { Very } \\
\text { Frequently }\end{array}$ \\
\hline
\end{tabular}

\section{Stem:}

When I am upset or unhappy...

1. I remind myself that if I just wait it out, I will eventually feel better.

2. I remember that other aspects of my life are going better.

3. I see myself as disconnected from other people.

4. I accept the situation and my reactions to it.

5. I struggle against the situation or my feelings.

6. I remind myself that I will grow from this experience.

7. I know that other areas of my life are going okay.

8. I do not trust that I will ever feel better.

9. I remind myself that painful experiences are a part of everyone's life.

10. I know I will be able to come to terms with this.

11. it seems like I will be changed for the worse by these problems.

12. I know that my perspective is going to change with time.

13. I feel isolated.

14. I reflect on how people I know have gone through similar situations.

15. there are things about my feelings that seem bad/shameful.

16. I know this situation will teach me things.

17. I understand that the situation will look different to me after some time passes.

18. I cannot help but notice a pattern of negative behavior in my life.

19. I feel like I cannot be as open to life after this.

20. it feels like I can live with this.

21. I view this as a part of life's lessons.

22. I assume that I will be dealing with my negative feelings for a long time. 
23. I stay aware of what I can do well.

24. I find inspiration in other people's experiences.

25 . it seems bad to let myself think too much about the problems I am having.

26. it feels like I will be wiser from this.

27. I lose perspective about better times.

28. I realize that this is only part of who I am.

29. I remind myself that what I am experiencing is something everyone feels.

30. I let myself experience my feelings.

31. I know there is value in painful experiences.

32. My problems feel worse than those of others.

33. I keep in mind that feelings change.

34. it seems like I am failing at everything.

35. I view my situation as worse than that of other people.

36. I remind myself that I have felt this bad before and come out of it.

37. I know that this is only part of my life.

38. I do not feel connected to others.

39. I feel I cannot stand these emotions.

40. I realize that I will learn from this.

41. I am aware that other people often feel the way that I do.

42. I remind myself that suffering is part of life.

43. it seems like the strong emotions will never end.

44. I know there is value in experiencing my emotions fully.

45. I view every part of my life negatively.

46. I remind myself that everyone suffers sometimes.

47. I lose my ability to think about positive things in my life.

48. I know I will be less trusting after this.

49. I know that others share experiences like mine.

50. I forget that I will not always feel this bad.

51. I feel as if I am somehow separated from other people.

52. I believe I will be more closed off after this.

53. I know that there are many ways to view the difficult situation.

54. it seems reasonable to feel the way that I do. 


\title{
Appendix D-1
}

\author{
Big Picture Appraisal Questionnaire
}

\section{Directions:}

Please think back to times when you have felt upset or unhappy. Many different situations provoke such feelings (e.g., when you felt you had failed or did not live up to your own or others' expectations, or when you experienced a loss, or felt rejected), and the emotions involved may vary (e.g., hurt, anger, sadness, grief, jealousy). Rate each of the following items on a scale from 1 to 5 to indicate how often you have had thoughts similar to those listed.

\section{Response Scale:}

\begin{tabular}{|c|c|c|c|c|}
\hline \multicolumn{5}{|c|}{ 1-------------------2--------------------3---------------------4--------------------5 } \\
\hline Never & Rarely & Sometimes & Frequently & $\begin{array}{l}\text { Very } \\
\text { Frequently }\end{array}$ \\
\hline
\end{tabular}

\section{Stem:}

When I am upset or unhappy...

1. I remember that other aspects of my life are going better.

2. I remind myself that I will grow from this experience.

3. I know that other areas of my life are going okay.

4. I remind myself that painful experiences are a part of everyone's life.

5. I know I will be able to come to terms with this.

6. I reflect on how people I know have gone through similar situations.

7. I know this situation will teach me things.

8. I understand that the situation will look different to me after some time passes.

9. I view this as a part of life's lessons.

10. I stay aware of what I can do well.

11. I find inspiration in other people's experiences.

12. it feels like I will be wiser from this.

13. I remind myself that what I am experiencing is something everyone feels.

14. I know there is value in painful experiences.

15. I remind myself that I have felt this bad before and come out of it.

16. I know that this is only part of my life.

17. I realize that I will learn from this.

18. I am aware that other people often feel the way that I do.

19. I remind myself that suffering is part of life.

20. I know there is value in experiencing my emotions fully.

21 . I remind myself that everyone suffers sometimes.

22. I know that others share experiences like mine.

23. I know that there are many ways to view the difficult situation 


\section{Appendix D-2}

Big Picture Appraisal Questionnaire as seen by Participants

Please think back to times when you have felt upset or unhappy. Many different situations provoke such feelings (e.g., when you felt you had failed or did not live up to your own or others' expectations, or when you experienced a loss, or felt rejected), and the emotions involved may vary (e.g., hurt, anger, sadness, grief, jealousy). Rate each of the following items on a scale from 1 to 5 to indicate how often you have had thoughts similar to those listed while dealing with upset or unhappy feelings.

When I am upset or unhappy...

\begin{tabular}{l|l} 
& $\begin{array}{c}1 \\
\text { Never }\end{array}$ \\
\hline I remember that other \\
aspects of my life are going \\
better. \\
I remind myself that I will \\
grow from this experience \\
I know that other areas of my \\
life are going okay. \\
I remind myself that painful \\
experiences are a part of \\
everyone's life. \\
I know I will be able to come \\
ko terms with this. \\
I reflect on how people I \\
know have gone through \\
similar situations. \\
I know this situation will \\
keach me things. \\
I understand that the \\
situation will look different to \\
me after some time passes. \\
I view this as a part of life's \\
lessons.
\end{tabular}




\section{Appendix E-1}

\section{Demographic Questions}

1. What is your sex?

2. What is your age?

3. Your class standing can best be described as:
a. Freshman
b. Sophomore
c. Junior
d. Senior
e. Graduate Student
f. Other (please specify)

4. Which of the following best describes your race/ethnicity?

a. African-American/Black (please specify ethnic group if applicable)

b. Hispanic-American/Latino/Chicano (please specify ethnic group if applicable)

c. Native American (please specify ethnic group if applicable)

d. Asian-American (please specify ethnic group if applicable)

e. Caucasian/European-American (please specify ethnic group if applicable)

f. Middle Eastern/Arab-American (please specify ethnic group if applicable)

g. Multiracial (please specify)

h. Other (please specify)

5. Please estimate your family's current household income (the family you grew up with)
a. Under $\$ 20,000$
b. $\$ 20,000$ to $\$ 34,999$
c. $\$ 35,000$ to $\$ 49,999$
d. $\$ 50,000$ to $\$ 64,999$
e. $\$ 65,000$ to $\$ 79,999$
f. $\$ 80,000$ to $\$ 94,999$
g. $\$ 95,000$ to $\$ 109,999$
h. $\$ 110,000$ to $\$ 124,999$
i. $\$ 125,000$ to $\$ 134,999$
j. $\$ 135,000$ to $\$ 149,999$
k. Over $\$ 150,000$ 
Appendix E-2

What is your sex?

Male

Female

What is your age?

Your class standing can best be described as:

Freshman

Sophomore

Junior

Senior

Graduate Student

Other (please specify) 


\section{Appendix F-1}

Short Form of the Marlowe-Crowne Social Desirability Scale

\section{Short Form Composite (13 items)}

1. I sometimes feel resentful when I don't get my way.

2. On a few occasions, I have given up doing something because I thought too little of my ability.

3. There have been times when I felt like rebelling against people in authority even though I knew they were right.

4. No matter who I'm talking to, I'm always a good listener.

5. I can remember "playing sick" to get out of something.

6. There have been occasions when I took advantage of someone.

7. I'm always willing to admit it when I make a mistake.

8. I sometimes try to get even rather than forgive and forget.

9. I am always courteous, even to people who are disagreeable.

10. I have never been irked when people expressed ideas very different from my own.

11. There have times when I was quite jealous of the good fortune of others.

12. I am sometimes irritated by people who ask favors of me.

13. I have never deliberately said something that hurt someone's feelings. 


\title{
Appendix F-2
}

\section{Short Form of the Marlowe-Crowne Social Desirability Scale as seen by Participants}

\begin{abstract}
Listed below are a number of statements concerning personal attitudes and traits. Read each item and decide whether the statement is true or false as it pertains to your personally. It's best to go with your first judgment and not spend too long mulling over any one question.
\end{abstract}

I sometimes feel resentful
when I don't get my way.
On a few occasions, I have
given up doing something
because I thought too little of
my ability.
There have been times when
I felt like rebelling against
people in authority even
though I knew they were
right.
No matter who I'm talking to,
I'm always a good listener.
I can remember "playing
sick" to get out of something.
There have been occasions
when I took advantage of
someone.
I'm always willing to admit
when I make a mistake.
I sometimes try to get even
rather than forgive and
forget.
I am always courteous, even
to people who are
disagreeable.




\section{Appendix G-1}

\section{Positive and Negative Affect Schedule}

(PANAS)

This scale consists of a number of words that describe different feelings and emotions. Read each item and then list the number from the scale below next to each word. Indicate to what extent you feel this way right now, that is, at the present moment OR indicate the extent you have felt this way over the past week (circle the instructions you followed when taking this measure)

1

Very slightly or

Not at all
2

A little
3

Moderately
4

Quite a bit
5

Extremely

1. Interested (1)

2. Distressed (2)

3. Excited (1)

4. Upset (2)

5. Strong (1)

6. Guilty (2)

7. Scared (2)

8. Hostile (2)

9. Enthusiastic (1)

10. Proud (1)

11. Irritable (2)

12. Alert (1)

13. Ashamed (2)

14. Inspired (1)

15. Nervous (2)

16. Determined (1)

17. Attentive (1)

18. Jittery (2)

19. Active (1)

20. Afraid (2)

*Note: Items marked with (1) are on the Positive Affect subscale. Items marked by (2) are on the Negative Affect subscale. 


\section{Appendix G-2}

Positive and Negative Affect Schedule as seen by Participants

This scale consists of a number of words that describe different feelings and emotions. Please indicate the degree to which the following words describe you at this moment. Right now I feel:

\begin{tabular}{l|ccccc} 
& $\begin{array}{c}1 \\
\text { Very Slightly } \\
\text { Or Not At } \\
\text { All }\end{array}$ & $\begin{array}{c}2 \\
\text { A Little }\end{array}$ & $\begin{array}{c}3 \\
\text { Moderately }\end{array}$ & $\begin{array}{c}4 \\
\text { Quite a Bit }\end{array}$ & $\begin{array}{c}5 \\
\text { Extremely }\end{array}$ \\
\hline Interested & 0 & 0 & 0 & 0 & 0 \\
Distressed & 0 & 0 & 0 & 0 \\
Excited & 0 & 0 & 0 & 0 & 0 \\
Upset & 0 & 0 & 0 & 0 & 0 \\
Strong & 0 & 0 & 0 & 0 \\
Guilty & 0 & 0 & 0 & 0 \\
Scared & 0 & 0 & 0 & 0 \\
Hostile & 0 & 0 & 0 & 0 \\
Enthusiastic & 0 & 0 & 0 & 0
\end{tabular}




\section{Appendix H-1}

The Big Five Inventory (BFI)

Here are a number of characteristics that may or may not apply to you. For example, do you agree that you are someone who likes to spend time with others? Please write a number next to each statement to indicate the extent to which you agree or disagree with that statement.

\begin{tabular}{|c|c|c|c|c|}
\hline $\mathbf{1}$ & $\mathbf{2}$ & $\mathbf{3}$ & $\mathbf{4}$ & $\mathbf{5}$ \\
$\begin{array}{c}\text { Disagree } \\
\text { Strongly }\end{array}$ & $\begin{array}{c}\text { Disagree } \\
\text { a little }\end{array}$ & $\begin{array}{c}\text { Neither agree } \\
\text { nor disagree }\end{array}$ & $\begin{array}{c}\text { Agree } \\
\text { a little }\end{array}$ & strongly \\
\hline
\end{tabular}

\section{I am someone who...}

1.

$$
2 .
$$
Is talkative

\section{3.} Tends to find fault with others

4. Does a thorough job
5. Is original, comes up with new ideas (2)

6. Is reserved

7. Is Is helpful and unselfish with others

8. _ Can be somewhat careless

9. ___ Is relaxed, handles stress well. (1)

10. Is curious about many different things (2)

11. __ Is full of energy

12. ___ Starts quarrels with others

13. ___ Is a reliable worker

14. Can be tense (1)

15. Is ingenious, a deep thinker (2)

16. Generates a lot of enthusiasm
17. Has a forgiving nature

18. Tends to be disorganized

19. Worries a lot (1)

20. Has an active imagination (2)

21. Tends to be quiet

22. Is generally trusting

23. Tends to be lazy

24. upset (1) Is emotionally stable, not easily

25. Is inventive (2)

26. Has an assertive personality

27. Can be cold and aloof

28. Perseveres until the task is finished

29. Can be moody (1)

30. Values artistic, aesthetic experiences (2)

31. Is sometimes shy, inhibited 
32. Is considerate and kind to almost everyone

33. ___ Does things efficiently

34. Remains calm in tense situations (1)

35. Prefers work that is routine (2)

36. ___ Is outgoing, sociable

37. Is sometimes rude to others

38. Makes plans and follows through with them

39. ___ Gets nervous easily (1)

40. ___ Likes to reflect, play with ideas (2)

41. __ Has few artistic interests (2)

42. L__ Likes to cooperate with others

43. ___ Is easily distracted

44. Is sophisticated in art, music, or literature. (2)

*Note: Items marked with (1) are on the Neuroticism subscale. Items marked by (2) are on the Openness subscale. 


\title{
Appendix H-2
}

\section{The Big Five Inventory (BFI) as seen by Participants}

\begin{abstract}
Here are a number of characteristics that may or may not apply to you. For example, do you agree that you are someone who likes to spend time with others? Please mark a number next to each statement to indicate the extent to which you agree or disagree with that statement.
\end{abstract}

I am someone who...

\begin{tabular}{|c|c|c|c|c|c|}
\hline & $\begin{array}{c}1 \\
\text { Disagree } \\
\text { Strongly }\end{array}$ & $\stackrel{2}{\text { Disagree a Little }}$ & $\begin{array}{c}3 \\
\text { Neither Agree } \\
\text { nor Disagree }\end{array}$ & $\begin{array}{c}4 \\
\text { Agree a Little }\end{array}$ & $\begin{array}{c}5 \\
\text { Agree Strongly }\end{array}$ \\
\hline is talkative & 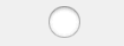 & 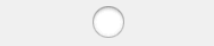 & & 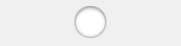 & \\
\hline tends to find fault with other & & & & & \\
\hline does a thorough job & & & & & \\
\hline is depressed, blue & & & & & \\
\hline $\begin{array}{l}\text { is original, comes up with } \\
\text { new ideas }\end{array}$ & & & & & \\
\hline is reserved & & & & & \\
\hline $\begin{array}{l}\text { is helpful and unselfish with } \\
\text { others }\end{array}$ & & & & & \\
\hline can be somewhat careless & & & & & \\
\hline $\begin{array}{l}\text { is relaxed, handles stress } \\
\text { well. }\end{array}$ & & & & & \\
\hline $\begin{array}{l}\text { is curious about many } \\
\text { different things }\end{array}$ & & & & & \\
\hline
\end{tabular}




\section{Appendix I-1}

\section{Emotion Regulation Questionnaire (ERQ)}

\section{Instructions and Items}

We would like to ask you some questions about your emotional life, in particular, how you control (that is, regulate and manage) your emotions. The questions below involve two distinct aspects of your emotional life. One is your emotional experience, or what you feel like inside. The other is your emotional expression, or how you show your emotions in the way you talk, gesture, or behave. Although some of the following questions may seem similar to one another, they differ in important ways.

Using the following 7-point scale, please answer the following questions about yourself by indicating the extent of your agreement:

\begin{tabular}{|l|l|l|l|l|l|l|l|}
\hline & $\begin{array}{l}\text { Strongly } \\
\text { Disagree }\end{array}$ & & & Neutral & & & $\begin{array}{l}\text { Strongly } \\
\text { Agree }\end{array}$ \\
\hline $\begin{array}{l}\text { 1. When I want to feel more } \\
\text { positive emotions (such as joy or } \\
\text { amusement) I change what I am } \\
\text { thinking about. (1) }\end{array}$ & 1 & 2 & 3 & 4 & 5 & 6 & 7 \\
\hline $\begin{array}{l}\text { 2. I keep my emotions to myself. } \\
\text { (2) }\end{array}$ & 1 & 2 & 3 & 4 & 5 & 6 & 7 \\
\hline $\begin{array}{l}\text { 3. When I want to feel less } \\
\text { negative emotion (such as sadness } \\
\text { or anger), I changes what I'm } \\
\text { thinking about. (1) }\end{array}$ & 1 & 2 & 3 & 4 & 5 & 6 & 7 \\
\hline $\begin{array}{l}\text { 4. When I'm feeling positive } \\
\text { emotions, I'm careful not to } \\
\text { express them. (2) }\end{array}$ & 1 & 2 & 3 & 4 & 5 & 6 & 7 \\
\hline $\begin{array}{l}\text { 5. When I'm faced with a stressful } \\
\text { situation, I make myself think } \\
\text { about it in a way that helps me } \\
\text { stay calm. (1) }\end{array}$ & 1 & 2 & 3 & 4 & 5 & 6 & 7 \\
\hline $\begin{array}{l}\text { 6. I control my emotions by not } \\
\text { expressing them. (2) }\end{array}$ & 1 & 2 & 3 & 4 & 5 & 6 & 7 \\
\hline $\begin{array}{l}\text { 7. When I want to feel more } \\
\text { positive emotion, I change the way } \\
\text { I am thinking about the situation. } \\
\text { (1) }\end{array}$ & 1 & 2 & 3 & 4 & 5 & 6 & 7 \\
\hline $\begin{array}{l}\text { 8. I control my emotions by } \\
\text { changing the way I think about the } \\
\text { situation. (1) }\end{array}$ & 1 & 2 & 3 & 4 & 5 & 6 & 7 \\
\hline
\end{tabular}




\begin{tabular}{|l|l|l|l|l|l|l|l|}
\hline $\begin{array}{l}\text { 9. When I'm feeling negative } \\
\text { emotions, I'm careful not to } \\
\text { express them. (2) }\end{array}$ & 1 & 2 & 3 & 4 & 5 & 6 & 7 \\
\hline $\begin{array}{l}\text { 10. When I want to feel less } \\
\text { negative emotion, I change the } \\
\text { way I'm thinking about the } \\
\text { situation. (1) }\end{array}$ & 1 & 2 & 3 & 4 & 5 & 6 & 7 \\
\hline
\end{tabular}

*Note: Items marked with (1) are on the Cognitive Reappraisal subscale. Items marked by (2) are on the Expressive Suppression subscale. 


\title{
Appendix I-2
}

\author{
Emotion Regulation Questionnaire (ERQ) as seen by Participants
}

This next questionnaire assesses how you control (that is, regulate and manage) your emotions. The questions below involve two distinct aspects of your emotional life. One is your emotional experience, or what you feel like inside. The other is your emotional expression, or how you show your emotions in the way you talk, gesture, or behave. Although some of the following questions may seem similar to one another, they differ in important ways.

\begin{tabular}{|c|c|c|c|c|c|c|c|}
\hline & $\begin{array}{c}1 \\
\text { Strongly } \\
\text { Disagree }\end{array}$ & 2 & 3 & $\begin{array}{c}4 \\
\text { Neutral }\end{array}$ & 5 & 6 & $\begin{array}{c}7 \\
\text { Strongly } \\
\text { Agree }\end{array}$ \\
\hline $\begin{array}{l}\text { 1. When I want to feel a } \\
\text { more positive emotion } \\
\text { (such as joy or } \\
\text { amusement), I change } \\
\text { what I'm thinking about. }\end{array}$ & & & & & & & \\
\hline $\begin{array}{l}\text { 1. I keep my emotions to } \\
\text { myself. }\end{array}$ & & & & & & & \\
\hline $\begin{array}{l}\text { 1. When I want to feel a less } \\
\text { negative emotion (such } \\
\text { as sadness or anger), I } \\
\text { change what I'm thinking } \\
\text { about. }\end{array}$ & & & & & & & \\
\hline $\begin{array}{l}\text { 1. When I am feeling } \\
\text { positive emotions, I am } \\
\text { careful not to express } \\
\text { them. }\end{array}$ & & & & & & & \\
\hline
\end{tabular}




\section{Appendix J-1}

Ruminative Responses Scale (RRS)

INSTRUCTIONS: Please read each of the items below and indicate how often, within the past 2 weeks, you have thought or done each one. Please indicate what you generally have done, not what you think you should do.

\begin{tabular}{|l|c|c|c|c|}
\hline & Almost Never & Sometimes & Often & $\begin{array}{c}\text { Almost } \\
\text { Always }\end{array}$ \\
\hline $\begin{array}{l}\text { Think "What am I } \\
\text { doing to deserve } \\
\text { this?" }\end{array}$ & 0 & 1 & 2 & 3 \\
\hline $\begin{array}{l}\text { Analyze recent } \\
\text { events to try to } \\
\text { understand why I am } \\
\text { depressed. }\end{array}$ & 0 & 1 & 2 & 3 \\
\hline $\begin{array}{l}\text { Think, "Why do I } \\
\text { always react this } \\
\text { way?" }\end{array}$ & 0 & 1 & 2 & 3 \\
\hline $\begin{array}{l}\text { Go away by myself } \\
\text { and think about why } \\
\text { I feel this way. }\end{array}$ & 0 & 1 & 2 & 3 \\
\hline $\begin{array}{l}\text { Write down what I } \\
\text { am thinking and } \\
\text { analyze it. }\end{array}$ & 0 & 1 & 2 & 3 \\
\hline $\begin{array}{l}\text { Think about a recent } \\
\text { situation, wishing it } \\
\text { had gone better. }\end{array}$ & 0 & 1 & 2 & 3 \\
\hline $\begin{array}{l}\text { Think, "Why do I } \\
\text { have problems other } \\
\text { people don't have?" }\end{array}$ & 0 & 1 & 2 & 3 \\
\hline $\begin{array}{l}\text { Think, "Why can't I } \\
\text { handle things } \\
\text { better?" }\end{array}$ & 0 & 1 & 2 & 3 \\
\hline $\begin{array}{l}\text { Analyze my } \\
\text { personality to try to } \\
\text { understand why I am } \\
\text { depressed. }\end{array}$ & 0 & & & 2 \\
\hline $\begin{array}{l}\text { Go someplace alone } \\
\text { to think about my } \\
\text { feelings. }\end{array}$ & 0 & 1 & & 3 \\
\hline
\end{tabular}




\section{Appendix J-2}

\section{Ruminative Responses Scale (RRS) as seen by Participants}

Please read each of the items below and indicate how often, within the past 2 weeks, you have thought or done each one. Please indicate what you generally have done, not what you think you should do.

\begin{tabular}{l|l} 
& Almost Never \\
Think "What am I doing to \\
deserve this?" \\
Analyze recent events to try \\
to understand why you are \\
depressed. \\
Think "Why do I always react \\
this way?" \\
Go away by yourself and \\
think about why you feel this \\
way. \\
Write down what you are \\
thinking an analyze it. \\
Think about a recent \\
situation, wishing it had gone \\
better. \\
Think "Why do I have \\
problems other people don't \\
have?" \\
Think, "Why can't I handle \\
things better?" \\
Analyze your personality and \\
try to understand why you \\
are depressed. \\
Go someplace alone to think \\
about your feelings.
\end{tabular}




\section{Appendix K-1}

\section{Self-Compassion Scale (SCS)}

Please read each statement carefully before answering. To the left of each item, indicate how often you behave in the stated manner, using the following scale:

Almost never

1

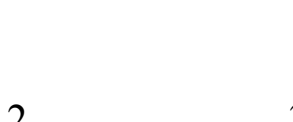

2

$\begin{array}{cc} & \text { Almost } \\ \text { always } \\ 4 & 5\end{array}$

Almost

1. I'm disapproving and judgmental about my own flaws and inadequacies.

2. When I'm feeling down I tend to obsess and fixate on everything that's wrong.

3. When things are going badly for me, I see the difficulties as part of life that everyone goes through.

4. When I think about my inadequacies, it tends to make me feel more separate and cut off from the rest of the world.

5. I try to be loving towards myself when I'm feeling emotional pain.

6. When I fail at something important to me I become consumed by feelings of inadequacy.

7. When I'm down and out, I remind myself that there are lots of other people in the world feeling like I am.

8. When times are really difficult, I tend to be tough on myself.

9. When something upsets me I try to keep my emotions in balance.

10. When I feel inadequate in some way, I try to remind myself that feelings of inadequacy are shared by most people.

11. I'm intolerant and impatient towards those aspects of my personality I don't like.

12. When I'm going through a very hard time, I give myself the caring and tenderness I need.

13. When I'm feeling down, I tend to feel like most other people are probably happier than I am. 
14. When something painful happens I try to take a balanced view of the situation. 15. I try to see my failings as part of the human condition.

16. When I see aspects of myself that I don't like, I get down on myself.

17. When I fail at something important to me I try to keep things in perspective.

18. When I'm really struggling, I tend to feel like other people must be having an easier time of it.

19. I'm kind to myself when I'm experiencing suffering.

20. When something upsets me I get carried away with my feelings.

21. I can be a bit cold-hearted towards myself when I'm experiencing suffering.

22. When I'm feeling down I try to approach my feelings with curiosity and openness.

23. I'm tolerant of my own flaws and inadequacies.

24. When something painful happens I tend to blow the incident out of proportion.

25. When I fail at something that's important to me, I tend to feel alone in my failure.

26. I try to be understanding and patient towards those aspects of my personality I don't like. 


\section{Appendix K-2}

\section{Self-Compassion Scale as seen by Participants}

This questionnaire assesses how you typically act towards yourself in difficult times. Please read each statement carefully before answering. To the right of each item, indicate how often you behave in the stated manner, using the given scale.

\begin{tabular}{|c|c|c|c|c|c|}
\hline & $\begin{array}{c}1 \\
\text { Almost Never }\end{array}$ & $\begin{array}{c}2 \\
\text { Occasionally }\end{array}$ & $\begin{array}{c}3 \\
\text { About Half of } \\
\text { the Time }\end{array}$ & $\begin{array}{c}4 \\
\text { Fairly Often }\end{array}$ & $\begin{array}{c}5 \\
\text { Almost always }\end{array}$ \\
\hline $\begin{array}{l}\text { I'm disapproving and } \\
\text { judgmental about my own } \\
\text { flaws and inadequacies. }\end{array}$ & 0 & 0 & 0 & 0 & 0 \\
\hline $\begin{array}{l}\text { When I'm feeling down I tend } \\
\text { to obsess and fixate on } \\
\text { everything that's wrong. }\end{array}$ & 0 & 0 & 0 & 0 & 0 \\
\hline $\begin{array}{l}\text { When things are going badly } \\
\text { for me, I see the difficulties } \\
\text { as part of life that everyone } \\
\text { goes through. }\end{array}$ & 0 & 0 & 0 & 0 & 0 \\
\hline $\begin{array}{l}\text { When I think about my } \\
\text { inadequacies, it tends to } \\
\text { make me feel more separate } \\
\text { and cut off from the rest of } \\
\text { the world. }\end{array}$ & 0 & 0 & 0 & 0 & 0 \\
\hline $\begin{array}{l}\text { I try to be loving towards } \\
\text { myself when I'm feeling } \\
\text { emotional pain. }\end{array}$ & 0 & 0 & 0 & 0 & 0 \\
\hline $\begin{array}{l}\text { When I fail at something } \\
\text { important to me I become } \\
\text { consumed by feelings of } \\
\text { inadequacy. }\end{array}$ & 0 & 0 & 0 & $\bigcirc$ & 0 \\
\hline $\begin{array}{l}\text { When I'm down, I remind } \\
\text { myself that there are lots of } \\
\text { other people in the world } \\
\text { feeling like I am. }\end{array}$ & 0 & $\bigcirc$ & 0 & 0 & 0 \\
\hline
\end{tabular}




\section{Appendix L-1}

\section{Difficulties in Emotion Regulation Scale (DERS)}

Please indicate how often the following statements apply to you by writing the appropriate number from the scale below on the line beside each item.

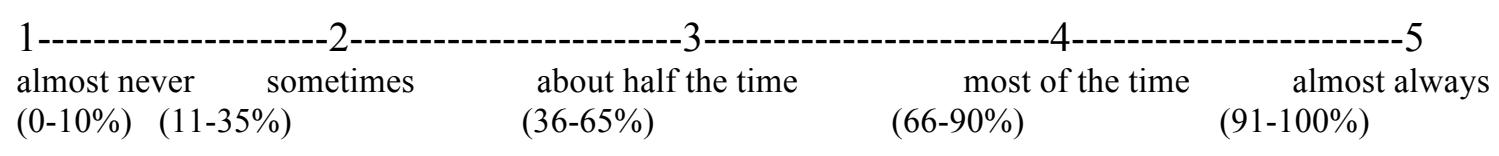

1) I am clear about my feelings.

2) I pay attention to how I feel.

3) I experience my emotions as overwhelming and out of control.

4) I have no idea how I am feeling.

5) I have difficulty making sense out of my feelings.

6) I am attentive to my feelings.

7) I know exactly how I am feeling.

8) I care about what I am feeling.

9) I am confused about how I feel.

10) When I'm upset, I acknowledge my emotions.

11) When I'm upset, I become angry with myself for feeling that way.

12) When I'm upset, I become embarrassed for feeling that way.

13) When I'm upset, I have difficulty getting work done.

14) When I'm upset, I become out of control.

15) When I'm upset, I believe that I will remain that way for a long time.

16) When I'm upset, I believe that I will end up feeling very depressed. 
17) When I'm upset, I believe that my feelings are valid and important.

18) When I'm upset, I have difficulty focusing on other things.

19) When I'm upset, I feel out of control.

20) When I'm upset, I can still get things done.

21) When I'm upset, I feel ashamed at myself for feeling that way.

22) When I'm upset, I know that I can find a way to eventually feel better.

23) When I'm upset, I feel like I am weak.

24) When I'm upset, I feel like I can remain in control of my behaviors.

25) When I'm upset, I feel guilty for feeling that way.

26) When I'm upset, I have difficulty concentrating.

27) When I'm upset, I have difficulty controlling my behaviors.

28) When I'm upset, I believe there is nothing I can do to make myself feel better.

29) When I'm upset, I become irritated at myself for feeling that way.

30) When I'm upset, I start to feel very bad about myself.

31) When I'm upset, I believe that wallowing in it is all I can do.

32) When I'm upset, I lose control over my behavior.

33) When I'm upset, I have difficulty thinking about anything else.

34) When I'm upset I take time to figure out what I'm really feeling.

35) When I'm upset, it takes me a long time to feel better.

36) When I'm upset, my emotions feel overwhelming. 


\section{Appendix L-2}

Difficulties in Emotion Regulation Scale (DERS) as seen by Participants

Please indicate how often the following statements apply to you based on the scale below.

\begin{tabular}{|c|c|c|c|c|c|}
\hline & $\begin{array}{c}1 \\
\text { Almost Never } \\
(0-10 \%)\end{array}$ & $\begin{array}{c}2 \\
\text { Sometimes } \\
(11-35 \%)\end{array}$ & $\begin{array}{c}3 \\
\text { About Half of } \\
\text { the Time } \\
(36-65 \%)\end{array}$ & $\begin{array}{c}4 \\
\text { Most of the } \\
\text { Time } \\
(66-90 \%)\end{array}$ & $\begin{array}{c}5 \\
\text { Almost Always } \\
(91-100 \%)\end{array}$ \\
\hline I am clear about my feelings. & O & 0 & O & O & O \\
\hline I pay attention to how I feel. & O & 0 & O & 0 & 0 \\
\hline $\begin{array}{l}\text { I experience my emotions as } \\
\text { overwhelming and out of } \\
\text { control. }\end{array}$ & O & O & $\bigcirc$ & O & $\bigcirc$ \\
\hline $\begin{array}{l}\text { I have no idea how I am } \\
\text { feeling. }\end{array}$ & $\bigcirc$ & O & $\bigcirc$ & O & $\bigcirc$ \\
\hline $\begin{array}{l}\text { I have difficulty making sense } \\
\text { out of my feelings. }\end{array}$ & O & O & $\bigcirc$ & O & O \\
\hline I am attentive to my feelings. & 0 & O & O & O & O \\
\hline $\begin{array}{l}\text { I know exactly how I am } \\
\text { feeling. }\end{array}$ & ○ & ○ & $\bigcirc$ & $\bigcirc$ & $\bigcirc$ \\
\hline $\begin{array}{l}\text { I care about how I am } \\
\text { feeling. }\end{array}$ & $\bigcirc$ & O & $\bigcirc$ & $\bigcirc$ & $\bigcirc$ \\
\hline $\begin{array}{l}\text { I am confused about how I } \\
\text { feel. }\end{array}$ & O & 0 & ○ & 0 & ○ \\
\hline $\begin{array}{l}\text { When I'm upset, I } \\
\text { acknowledge my emotions. }\end{array}$ & 0 & O & O & O & $\bigcirc$ \\
\hline $\begin{array}{l}\text { When I'm upset, I become } \\
\text { angry with myself for feeling } \\
\text { that way. }\end{array}$ & O & O & $\bigcirc$ & O & 0 \\
\hline $\begin{array}{l}\text { When I'm upset, I become } \\
\text { embarrassed for feeling that } \\
\text { way. }\end{array}$ & 0 & O & O & O & 0 \\
\hline
\end{tabular}




\section{Appendix M-1}

\section{Mindful Attention Awareness Scale (MAAS)}

Instructions: Below is a collection of statements about your everyday experience. Using the 1-6 scale below, please indicate how frequently or infrequently you currently have each experience. Please answer according to what really reflects your experience rather than what you think your experience should be. Please treat each item separately from every other item.

\begin{tabular}{|c|c|c|c|c|c|c|}
\hline & $\begin{array}{l}\text { Almost } \\
\text { Always }\end{array}$ & $\begin{array}{l}\text { Very } \\
\text { Frequently }\end{array}$ & $\begin{array}{l}\text { Somewhat } \\
\text { Frequently }\end{array}$ & $\begin{array}{l}\text { Somewhat } \\
\text { Infrequently }\end{array}$ & $\begin{array}{l}\text { Very } \\
\text { Infrequently }\end{array}$ & $\begin{array}{l}\text { Almost } \\
\text { Never }\end{array}$ \\
\hline $\begin{array}{l}\text { I could be experiencing } \\
\text { some emotion and not } \\
\text { be conscious of it until } \\
\text { some time later. }\end{array}$ & 1 & 2 & 3 & 4 & 5 & 6 \\
\hline $\begin{array}{l}\text { I break or spill things } \\
\text { because of } \\
\text { carelessness, not } \\
\text { paying attention, or } \\
\text { thinking of something } \\
\text { else. }\end{array}$ & 1 & 2 & 3 & 4 & 5 & 6 \\
\hline $\begin{array}{l}\text { I find it difficult to stay } \\
\text { focused on what's } \\
\text { happening in the } \\
\text { present. }\end{array}$ & 1 & 2 & 3 & 4 & 5 & 6 \\
\hline $\begin{array}{l}\text { I tend to walk quickly } \\
\text { to get to where I'm } \\
\text { going without paying } \\
\text { attention to what I } \\
\text { experience along the } \\
\text { way. }\end{array}$ & 1 & 2 & 3 & 4 & 5 & 6 \\
\hline $\begin{array}{l}\text { I tend not to notice } \\
\text { feelings of physical } \\
\text { tension or discomfort } \\
\text { until they really grab } \\
\text { my attention. }\end{array}$ & 1 & 2 & 3 & 4 & 5 & 6 \\
\hline $\begin{array}{l}\text { I forget a person's } \\
\text { name almost as soon as } \\
\text { I've been told it for the } \\
\text { first time. }\end{array}$ & 1 & 2 & 3 & 4 & 5 & 6 \\
\hline $\begin{array}{l}\text { It seems I am "running } \\
\text { on automatic" without } \\
\text { much awareness of } \\
\text { what I'm doing. }\end{array}$ & 1 & 2 & 3 & 4 & 5 & 6 \\
\hline $\begin{array}{l}\text { I rush through } \\
\text { activities without being } \\
\text { really attentive to } \\
\text { them. }\end{array}$ & 1 & 2 & 3 & 4 & 5 & 6 \\
\hline
\end{tabular}




\begin{tabular}{|l|c|c|c|c|c|c|}
\hline $\begin{array}{l}\text { I get so focused on the } \\
\text { goal I want to achieve } \\
\text { that I lose touch of } \\
\text { what I'm doing right } \\
\text { now to get there. }\end{array}$ & 1 & 2 & 3 & 4 & 5 & 6 \\
\hline $\begin{array}{l}\text { I do jobs or tasks } \\
\text { automatically, without } \\
\text { being aware of what }\end{array}$ & 1 & 2 & 3 & 4 & 5 & 6 \\
I'm doing.
\end{tabular}




\section{Appendix M-2}

Mindful Attention Awareness Scale as seen by Participants

Instructions: Below is a collection of statements about your everyday experience. Using the 1-6 scale below, please indicate how frequently or infrequently you currently have each experience. Please answer according to what really reflects your experience rather than what you think your experience should be. Please treat each item separately from every other item.

\begin{tabular}{|c|c|c|c|c|c|c|}
\hline & $\begin{array}{c}\text { Almost } \\
\text { Always } \\
1\end{array}$ & $\begin{array}{c}\text { Very } \\
\text { Frequently } \\
\quad 2\end{array}$ & $\begin{array}{c}\text { Somewhat } \\
\text { Frequently } \\
\quad 3\end{array}$ & $\begin{array}{c}\text { Somewhat } \\
\text { Infrequently } \\
\mathbf{4}\end{array}$ & $\begin{array}{c}\text { Very } \\
\text { Infrequently } \\
5\end{array}$ & $\begin{array}{c}\text { Almost } \\
\text { Never } \\
6\end{array}$ \\
\hline $\begin{array}{l}\text { I could be experiencing some } \\
\text { emotion and not be } \\
\text { conscious of it until some } \\
\text { time later. }\end{array}$ & 0 & 0 & 0 & 0 & 0 & 0 \\
\hline $\begin{array}{l}\text { I break or spill things } \\
\text { because of carelessness, not } \\
\text { paying attention, or thinking } \\
\text { of something else. }\end{array}$ & 0 & 0 & 0 & 0 & 0 & 0 \\
\hline $\begin{array}{l}\text { I find it difficult to stay } \\
\text { focused on what's happening } \\
\text { in the present. }\end{array}$ & 0 & 0 & 0 & 0 & 0 & 0 \\
\hline $\begin{array}{l}\text { I tend to walk quickly to get } \\
\text { to where I'm going without } \\
\text { paying attention to what I } \\
\text { experience along the way. }\end{array}$ & 0 & 0 & 0 & 0 & 0 & 0 \\
\hline $\begin{array}{l}\text { I tend not to notice feelings of } \\
\text { physical tension or } \\
\text { discomfort until they really } \\
\text { grab my attention. }\end{array}$ & 0 & 0 & 0 & 0 & 0 & 0 \\
\hline $\begin{array}{l}\text { I forget a person's name } \\
\text { almost as soon as I've been } \\
\text { told it for the first time. }\end{array}$ & 0 & 0 & 0 & 0 & 0 & 0 \\
\hline $\begin{array}{l}\text { It seems I am "running on } \\
\text { automatic" without much } \\
\text { awareness of what I'm doing. }\end{array}$ & 0 & 0 & 0 & 0 & 0 & 0 \\
\hline
\end{tabular}




\section{Appendix N-1}

The Behavior Identification Form (BIF)

Any behavior can be described in many ways. For example, on person might describe a behavior as "writing a paper," while another person might describe the same behavior as "pushing keys on the keyboard." Yet another person might describe it as "expressing thoughts." This form focuses on your personal preferences for how a number of different behaviors could be described. Below you will find several behaviors listed. After each behavior will be two different ways in which the behavior might be identified. For example:

1. Attending class

a. Sitting in a chair

b. Looking at a teacher

Your task is to choose the identification, $a$ or $b$, that best describes the behavior for you. Simply place a checkmark next to the option you prefer. Be sure to respond to every item. Please mar only one alternative for each pair. Remember, mark the description that you personally believe is more appropriate for each pair.

1. Making a list

a. Getting organized

b. Writing things down

2. Reading

a. Following lines of print

b. Gaining knowledge

3. Joining the army
a. Helping the nation's defense
b. Signing up

4. Washing clothes
a. Removing odors from clothes
b. Putting clothes into the machine

5. Picking an apple
a. Getting something to eat
b. Pulling an apple off a branch

6. Chopping down a tree
a. Wielding an axe
b. Getting firewood

7. Measuring a room for carpet

a. Getting ready to remodel b. Using a yard stick

8. Cleaning the house
a. Showing one's cleanliness
b. Vacuuming the floor

9. Painting a room

a. Applying brushstrokes

b. Making the room look fresh

10. Paying the rent
a. Maintaining a place to live

b. Writing a check

11. Caring for houseplants

a. Watering plants

b. Making the room look nice

12. Locking a door

13. Voting

a. Putting a key in the lock

b. Securing the house

a. Influencing the election

b. Marking a ballot 
14. Climbing a tree

a. Getting a good view

b. Holding onto branches

15. Filling out a personality test

a. Answering questions

b. Revealing what you're like

16. Tooth brushing

a. Preventing took decay

b. Moving a brush around in one's mouth

17. Taking a test

a. Answering questions

b. Showing one's knowledge

18. Greeting someone

a. Saying hello

b. Showing friendliness

19. Resisting temptation

a. Saying "no"

b. Showing moral courage

20. Eating

a. Getting nutrition

b. Chewing and swallowing

21. Growing a garden

a. Planting seeds

b. Getting fresh vegetables

22. Traveling by car

a. Following a map

b. Seeing countryside

23. Having a cavity filled

a. Protecting your teeth

b. Going to the dentist

24. Talking to a child
a. Teaching a child something
b. Using simple words

25. Pushing a doorbell

a. Moving a finger

b. Seeing if someone's home 


\section{Appendix N-2}

The Behavior Identification Form (BIF) as seen by Participants

Any behavior can be described in many ways. For example, one person might describe a behavior as "writing a paper," while another person might describe the same behavior as "pushing keys on the keyboard." Yet another person might describe it as "expressing thoughts." This form focuses on your personal preferences for how a number of different behaviors could be described. Next you will find several behaviors listed. After each behavior will be two different ways in which the behavior might be identified. For example:

1. Attending class

a. Sitting in a chair

b. Looking at a teacher

Your task is to choose the identification, $a$ or $b$, that best describes the behavior for you. Simply select the option you prefer. Be sure to respond to every item. Remember, select the description that you personally believe is more appropriate for each pair.

Making a list

Getting organized

Writing things down 


\section{Appendix 0-1}

\section{Experiences Questionnaire (EQ)}

Please use the following scale to answer the items listed below.

Never

1

2

3

4

All the time

5

1. I think about what will happen in the future

2. I remind myself that thoughts aren't facts.

3. I am better able to accept myself as I am. (1)

4. I notice all sorts of little things and details in the world around me.

5. I am kinder to myself when things go wrong. (1)

6. I can slow my thinking at times of stress. (1)

7. I wonder what kind of person I really am.

8. I am not so easily carried away by my thoughts and feelings. (1)

9. I notice that I don't take difficulties so personally. (1)

10. I can separate myself from my thoughts and feelings. (1)

11. I analyze why things turn out the way they do.

12. I can take time to respond to difficulties. (1)

13. I think over and over again about what others have said to me.

14. I can treat myself kindly. (1)

15. I can observe unpleasant feelings without being drawn into them. (1)

16. I have the sense that I am fully aware of what is going on around me and inside me. (1)

17. I can actually see that I am not my thoughts. (1)

18. I am consciously aware of a sense of my body as a whole. (1)

19. I think about the ways in which I am different from other people.

20. I view things from a wider perspective. (1)

*Note: Items marked with (1) are on the Decentering subscale. 


\section{Appendix 0-2}

Experiences Questionnaire (EQ) as seen by Participants

Please think about how you react to difficult situations now compared to how you have reacted to difficult situations that occurred more than a year ago. Then use the following scale to answer the items listed below.

I think about what will
happen in the future.
I remind myself that thoughts
aren't facts.
I am better able to accept
myself as I am.
I notice all sorts of little things
and details in the world
around me.
I am kinder to myself when
things go wrong.
I can slow my thinking down
in times of stress.
I wonder what kind of person
I really am.
I am not so easily carried
away by my thoughts and
feelings.
I notice that I don't take
difficulties so personally.
I can separate myself from
my thoughts and my feelings.
I analyze why things turn out
the way they do.
I can take time to respond to
difficulties.




\section{Appendix P-1}

\section{Cognitive Flexibility Inventory (CFI)}

Please use the scale below to indicate the extent to which you agree or disagree with the following statements.

$\begin{array}{ccccccc}1 & 2 & 3 & 4 & 5 & 6 & 7 \\ \begin{array}{c}\text { Strongly } \\ \text { Disagree }\end{array} & \text { Disagree } & \begin{array}{c}\text { Somewhat } \\ \text { Disagree }\end{array} & \text { Neutral } & \begin{array}{c}\text { Somewhat } \\ \text { Agree }\end{array} & \text { Agree } & \begin{array}{c}\text { Strongly } \\ \text { Agree }\end{array}\end{array}$

1. I am good at "sizing up" situations. (1)

2. I have a hard time making decisions when faced with difficult situations. (2)

3. I consider multiple options before making a decision. (1)

4. When I encounter difficult situations, I feel like I am losing control. (2)

5. I like to look at difficult situations from many different angles. (1)

6. I seek additional information not immediately available before attributing causes to behavior. (1)

7. When encountering difficult situations, I become so stressed that I cannot think of a way to resolve the situation. (2)

8. I try to think about things from another person's point of view. (1)

9. I find it troublesome that there are so many different ways to deal with difficult situations. (2)

10. I am good at putting myself in others' shoes. (1)

11. When I encounter difficult situations, I just don't know what to do. (2)

12. It is important to look at difficult situations from many angles. (1)

13. When in difficult situations, I consider multiple options before deciding how to behave. (1)

14. I often look at a situation from different viewpoints. (1)

15. I am capable of overcoming the difficulties in life that I face. (2)

16. I consider all available facts and information when attributing causes to behavior. (1)

17. I feel I have no power to change things in difficult situations. (2)

18. When I encounter difficult situations, I stop and try to think of several ways to resolve it. (1)

19. I can think of more than one way to resolve a difficult situation I'm confronted with. (1)

20. I consider multiple options before responding to difficult situations. (1)

*Note: Items marked with (1) are on the Alternatives subscale. Items marked by (2) are on the Control subscale. 


\section{Appendix P-2}

Cognitive Flexibility Inventory (CFI) as seen by Participants

Please use the scale below to indicate the extent to which you agree or disagree with the following statements.

\begin{tabular}{l|lllll} 
& $\begin{array}{c}\text { Strongly } \\
\text { Disagree }\end{array}$ & $\begin{array}{c}\text { Somewhat } \\
\text { Disagree } \\
\text { Disagree }\end{array}$ & $\begin{array}{c}\text { Soutral } \\
\text { Agree }\end{array}$ & $\begin{array}{c}\text { Strongl! } \\
\text { Agree }\end{array}$ \\
\hline $\begin{array}{l}\text { I am good at "sizing up" } \\
\text { situations. } \\
\text { I have a hard time making } \\
\text { decisions when faced with } \\
\text { difficult situations. }\end{array}$ & & & & \\
I consider multiple options \\
before making a decision. \\
$\begin{array}{l}\text { When I encounter difficult } \\
\text { situations, I feel like I am } \\
\text { losing control. }\end{array}$
\end{tabular}




\section{Appendix R-1}

\section{Social Readjustment Rating Scale (SRRS)}

Please mark all of the life events that have happened to you in the last year.

1. Death of a spouse

2. Divorce

3. Marital separation

4. Jail term

5. Death of a close family member

6 . Personal injury or illness

7. Marriage

8. Fired at work

9. Marital reconciliation

10. Retirement

11. Change in health of family member

12. Pregnancy

13. Sex difficulties

14. Gain of a new family member

15. Business readjustments

16. Change in financial state

17. Death of a close friend

18. Change to different line of work

19. Change in number of arguments with spouse

20. Mortgage over $\$ 50,000$

21. Foreclosure of mortgage

22. Change in responsibilities at work

23. Son or daughter leaving home

24. Trouble with in-laws

25. Outstanding Personal achievements

26. Spouse begins or stops work

27. Begin or end school

28. Change in living conditions

29. Revision of personal habits

30. Trouble with boss

31. Change in work hours or conditions

32. Change in residence

33. Change in school

34. Change in recreation

35. Change in religious activities

36. Change in social activities

37. Loan less than 50,000 
38. Change in sleeping habits

39. Change in number of family get- together

40. Change in eating habits

41. Vacation

42. Holidays

43. Minor violation of laws 


\section{Appendix R-2}

Social Readjustment Rating Scale (SRRS) as seen by Participants

Please indicate whether you have experienced the following life events in the last year.

\begin{tabular}{|c|c|c|}
\hline & Yes & No \\
\hline Death of a spouse & 0 & O \\
\hline Divorce & O & O \\
\hline Marital separation & $\bigcirc$ & O \\
\hline Jail term & O & O \\
\hline $\begin{array}{l}\text { Death of a close family } \\
\text { member }\end{array}$ & 0 & $\bigcirc$ \\
\hline Personal injury or illness & O & O \\
\hline Marriage & $\bigcirc$ & O \\
\hline Fired at work & $\bigcirc$ & O \\
\hline Marital reconciliation & 0 & 0 \\
\hline Retirement & 0 & O \\
\hline $\begin{array}{l}\text { Change in health of family } \\
\text { member }\end{array}$ & O & 0 \\
\hline Pregnancy & O & 0 \\
\hline Sex difficulties & O & O \\
\hline Gain of a new family member & O & 0 \\
\hline \multirow[t]{2}{*}{ Business readjustments } & 0 & O \\
\hline & Yes & No \\
\hline
\end{tabular}




\section{Appendix S-1}

\section{Short-Form CES-D}

For each statement, please indicate the column that best describes how you have been feeling in the past two weeks.

\begin{tabular}{|l|l|l|l|l|}
\hline & $\begin{array}{c}1 \\
\text { Rarely or none of } \\
\text { the time }\end{array}$ & $\begin{array}{c}1 \\
\text { Some or a little } \\
\text { of the time }\end{array}$ & $\begin{array}{c}2 \\
\text { Occasionally or a } \\
\text { moderate amount } \\
\text { of the time }\end{array}$ & $\begin{array}{c}3 \\
\text { Most or all of the } \\
\text { time }\end{array}$ \\
\hline $\begin{array}{l}\text { 1. I was bothered by } \\
\text { things that usually } \\
\text { don't bother me. }\end{array}$ & & & \\
\hline $\begin{array}{l}\text { 2. I felt that I could } \\
\text { not shake off the } \\
\text { blues even with the } \\
\text { help from my } \\
\text { friends or family. }\end{array}$ & & & & \\
\hline $\begin{array}{l}\text { 3. I felt that I was } \\
\text { just as good as other } \\
\text { people. }\end{array}$ & & & & \\
\hline $\begin{array}{l}\text { 4. I had trouble } \\
\text { keeping my mind on } \\
\text { what I was doing. }\end{array}$ & & & & \\
\hline $\begin{array}{l}\text { 5. I felt that } \\
\text { everything I did was } \\
\text { an effort. }\end{array}$ & & & & \\
\hline $\begin{array}{l}\text { 6. I felt hopeful } \\
\text { about the future. }\end{array}$ & & & & \\
\hline $\begin{array}{l}\text { 7. I felt my life had } \\
\text { been a failure. }\end{array}$ & & & & \\
\hline 8. I felt fearful. & & & & \\
\hline 9. I felt lonely. & & & & \\
\hline $\begin{array}{l}\text { 10. People were } \\
\text { unfriendly. }\end{array}$ & & & & \\
\hline
\end{tabular}




\section{Appendix S-2}

CES-D as seen by Participants

For each statement, please indicate the response that best describes how you have been feeling in the past two weeks.

\begin{tabular}{|c|c|c|c|c|}
\hline & $\begin{array}{c}\text { Rarely or none of } \\
\text { the time } \\
0\end{array}$ & $\begin{array}{c}\text { Some or a little of } \\
\text { the time } \\
1\end{array}$ & $\begin{array}{c}\text { Occasionally or a } \\
\text { moderate amount } \\
\text { of the time } \\
2\end{array}$ & $\begin{array}{c}\text { Most or all of the } \\
\text { time } \\
3\end{array}$ \\
\hline $\begin{array}{l}\text { I was bothered by things that } \\
\text { usually don't bother me. }\end{array}$ & O & O & O & O \\
\hline $\begin{array}{l}\text { I felt that I could not shake off } \\
\text { the blues even with the help } \\
\text { from my family or friends. }\end{array}$ & 0 & O & O & O \\
\hline $\begin{array}{l}\text { I felt that I was just as good } \\
\text { as other people. }\end{array}$ & D & O & O & O \\
\hline $\begin{array}{l}\text { I had trouble keeping my } \\
\text { mind on what I was doing. }\end{array}$ & & 0 & O & O \\
\hline $\begin{array}{l}\text { I felt that everything I did was } \\
\text { an effort. }\end{array}$ & & O & O & O \\
\hline I felt hopeful about the future. & & O & O & O \\
\hline $\begin{array}{l}\text { I felt my life had been a } \\
\text { failure. }\end{array}$ & O & $\bigcirc$ & O & O \\
\hline I felt fearful. & & O & O & 0 \\
\hline I felt lonely. & & O & O & O \\
\hline \multirow[t]{2}{*}{ People were unfriendly. } & 0 & O & 0 & O \\
\hline & $\begin{array}{c}\text { Rarely or none of } \\
\text { the time } \\
0\end{array}$ & $\begin{array}{c}\text { Some or a little of } \\
\text { the time } \\
1\end{array}$ & $\begin{array}{c}\text { Occasionally or a } \\
\text { moderate amount } \\
\text { of the time } \\
2\end{array}$ & $\begin{array}{c}\text { Most or all of the } \\
\text { time } \\
\mathbf{3}\end{array}$ \\
\hline
\end{tabular}




\section{References}

Aldoa, A., Nolen-Hoeksema, S., \& Schweizer, S. (2010). Emotion-regulation strategies across psychopathology: A meta-analytic review. Clinical Psychology Review, $30,217-237$.

Ayduk, O., \& Kross, E. (2010). From a distance: Implications of spontaneous selfdistancing for adaptive self-reflection. Journal of Personality and Social Psychology, 98(5), 809-829.

Ballard, R. (1992). Short forms of the Marlowe-Crowne Social Desirability Scale. Psychological Reports, 71(3, Pt 2), 1155-1160.

Barnard, L. K., \& Curry, J. F. (2011). Self-compassion: Conceptualizations, correlates, \& interventions. Review Of General Psychology, 15(4), 289-303.

Baum, E.S., \& Rude, S.S. (under review, Cognitive Therapy and Research, April, 2011). The effects of expressive writing with and without emotion acceptance instructions on depression symptoms.

Beck, A. T., Rush, A. J., Shaw, B. F., \& Emery, G. (1979). Cognitive therapy of depression. New York: Guilford.

Bishop, S. R., Lau, M., Shapiro, S., Carlson, L., Anderson, N. D., Carmody, J. et al. (2004). Mindfulness: A proposed operational definition. Clinical Psychology: Science and Practice, 11(3), 230-241.

Broderick, P. C. (2005). Mindfulness and coping with dysphoric mood: Contrasts with rumination and distraction. Cognitive Therapy and Research, 29(5), 501-510. 
Brown, T. A. (2006). Confirmatory Factor Analysis for Applied Research. New York: Guilford Publications.

Brown, K. W., \& Ryan, R. M. (2003). The benefits of being present: The role of mindfulness in psychological well-being. Journal of Personality and Social Psychology, 84, 822-848.

Cahn, B. R., \& Polich, J. (2006). Meditation states and traits: EEG, ERP, and neuroimaging studies. Psychological Bulletin, 132, 180-211.

Campbell-Sills, L., Barlow, D. H., Brown, T. A., \& Hofmann, S. G. (2006). Effects of suppression and acceptance on emotional responses of individuals with anxiety and mood disorders. Behaviour Research and Therapy, 44(9), 1251-1263.

Carlson, L. E., Speca, M., Patel, K. D., \& Goodey, E. (2004). Mindfulness-based stress reduction in relation to quality of life, mood, symptoms of stress and levels of cortisol, dehydroepiandrosterone sulfate (DHEAS) and melatonin in breast and prostate cancer outpatients. Psychoneuroendocrinology, 29(4), 448-474.

Cole, J. C., Rabin, A. S., Smith, T. L., \& Kaufman, A. S. (2004). Development and validation of a Rasch-derived CES-D short form. Psychological Assessment, 16(4), 360-372.

Crowne, D. P., \& Marlowe, D. (1 960). A new scale of social desirability independent of psychopathology. Journal of Consulting Psychology, 24, 349-354. 
Cudeck, R. (2000). Exploratory factor analysis. In H. A. Tinsley, S. D. Brown, H. A. Tinsley, S. D. Brown (Eds.), Handbook of applied multivariate statistics and mathematical modeling (pp. 265-296). San Diego, CA US: Academic Press.

Dawis, R. V. (2000). Scale construction and psychometric considerations. In H. A. Tinsley, S. D. Brown, H. A. Tinsley, S. D. Brown (Eds.), Handbook of applied multivariate statistics and mathematical modeling (pp. 65-94). San Diego, CA

US: Academic Press.

Fresco, D. M., Moore, M. T., van Dulmen, M. M., Segal, Z. V., Ma, S., Teasdale, J. D., \& Williams, J. G. (2007). Initial psychometric properties of the Experiences Questionnaire: Validation of a self-report measure of decentering. Behavior Therapy, 38(3), 234-246.

Gratz, K. L., \& Roemer, L. (2004). Multidimensional assessment of emotion regulation and dysregulation: Development, factor structure, and initial validation of the difficulties in emotion regulation scale. Journal of Psychopathology and Behavioral Assessment, 26(1), 41-54.

Greeno, C. G., \& Wing, R. R. (1994). Stress-induced eating. Psychological Bulletin, 115, 444-464.

Gross, J. J. (1998). Antecedent- and response-focused emotion regulation: Divergent consequences for experience, expression, and physiology. Journal of Personality and Social Psychology, 74(1), 224-237. 
Gross, J.J. (1998). The emerging field of emotion regulation: An integrative review. Review of General Psychology, 2(3), 271-299.

Gross, J. J., (2002). Emotion regulation: Affective, cognitive, and social consequences. Psychophysiology, 39, 281-291

Gross, J.J., \& John, O. P. (2003). Individual difference in two emotion regulation processes: Implications for affect, relationships, and well-being. Journal of Personality and Social Psychology, 85(2), 348-362.

Gross, J.J., Richards, J.M., \& John, O.P. (in press). Emotion regulation in everyday life. In D.K. Snyder, J.A. Simpson, \& J.N. Hughes (Eds.). Emotion regulation in families: Pathways to dysfunction and health. Washington DC: American Psychological Association.

Gross, J. J., \& Thompson, R. A. (2007). Emotion regulation: Conceptual foundations. In J. J. Gross (Ed.), Handbook of Emotion Regulation (pp. 3-24). New York, N.Y.: Guilford Press.

Hayes, S. (Ed.), Follette, V. (Ed.), \& Linehan, M. (Ed.). (2004). Mindfulness and acceptance: Expanding the cognitive-behavioral tradition. New York, NY US: Guilford Press.

Hayes, S. C., Strosahl, K. D., \& Wilson, K. G. (1999). Acceptance and Commitment Therapy: An experiential approach to behavior change. New York: Guilford Press. 
Hill, C. M., \& Updegraff, J. A. (2011). Mindfulness and its relationship to emotional regulation. Emotion. Advance online publication. doi: 10.1037/a0026355

Hill, C. E. (2009). Emotion theory and research: Highlights, unanswered questions, and emerging issues. Annual Review of Psychology, 60, 1-25.

Holmes, T. H., \& Rahe, R. H. (1967). The social readjustment rating scale. Journal of Psychosomatic Research, 11(2), 213-218.

Hodgins, H. S., \& Knee, C. R. (2002). The integrating self and conscious experience. In E. L. Deci \& R. M. Ryan (Eds.), Handbook of self-determination research (pp. 87-100). Rochester, NY: University of Rochester Press.

Hong, R. Y. (2007). Worry and rumination: Differential associations with anxious and depressive symptoms and coping behaviors. Behavior Research and Therapy, $45,277-290$.

Huffziger, S., \& Kuehner, C. (2009). Rumination, distraction, and mindful self-focus in depressed patients. Behaviour Research and Therapy, 47(3), 224-230.

John, O. P., Donahue, E. M., \& Kentle, R. L. (1991). The Big Five Inventory--Versions 4a and 54. Berkeley, CA: University of California, Berkeley, Institute of Personality and Social Research.

John, O. P., Naumann, L. P., \& Soto, C. J. (2008). Paradigm shift to the integrative Big Five trait taxonomy: History, measurement, and conceptual issues. In O. P. John, R. W. Robins, \& L. A. Pervin (Eds.), Handbook of personality: Theory and Research (pp. 114-158). New York, NY: Guilford Press 
Kabat-Zinn, J. (1982). An outpatient program in behavioral medicine for chronic pain patients based on the practice of mindfulness meditation: Theoretical consideration and preliminary results. General Hospital Psychiatry, 4, 33-47.

Kabat-Zinn, J., Lipworth, L., \& Burney, R. (1985). The clinical use of mindfulness meditation for the self-regulation of chronic pain. Journal of Behavioral Medicine, 8(2), 163-190.

Keng, S., Smoski, M. J., \& Robins, C. J. (2011). Effects of mindfulness on psychological health: A review of empirical studies. Clinical Psychology Review, 31(6), 10411056.

Kline, R. B. (2011). Principles and practice of structural equation modeling. New York, NY: Guilford Press.

Koole, S. L. (2009). The psychology of emotion regulation: An integrative review. Cognition and Emotion, 23(1), 4-41.

Knuuttila, S. (2006). Emotions in ancient and medieval philosophy. New York, N.Y.: Oxford University Press.

Kross, E., \& Ayduk, O. (2008). Facilitating adaptive emotional analysis: Distinguishing distanced-analysis of depressive experiences from immersed-analysis and distraction. Personality And Social Psychology Bulletin, 34(7), 924-938.

Kross, E., \& Ayduk, O. (2011). Making meaning out of negative experiences by selfdistancing. Current Directions in Psychological Science, 20, 187-191. 
Kross, E., Ayduk, O., \& Mischel, W. (2005). When Asking 'Why' Does Not Hurt: Distinguishing Rumination From Reflective Processing of Negative Emotions. Psychological Science, 16(9), 709-715.

Kross, E., Gard, D., Deldin, P., Clifton, J., \& Ayduk, O. (2012). “Asking why” from a distance: Its cognitive and emotional consequences for people with major depressive disorder. Journal of Abnormal Psychology, 121(3), 559-569.

Krpan, K. M., Kross, E., Berman, M. G., Deldin, P. J., Askren, M. K., \& Jonides, J. (2013). An everyday activity as a treatment for depression: The benefits of expressive writing for people diagnosed with major depressive disorder. Journal of Affective Disorders.

Kumar, S., Feldman, G., \& Hayes, A. (2008). Changes in mindfulness and emotion regulation in an exposure-based cognitive therapy for depression. Cognitive Therapy and Research, 32(6), 734-744.

Lau, M. A., Bishop, S. R., Segal, Z. V., Buis, T., Anderson, N. D., Carlson, L.,..., \& Devins, G. (2006). The Toronto Mindfulness Scale: Development and validation. Journal of Clinical Psychology, 62(12), 1445-1467.

Lazarus, R. S.. \& Alfert. E. (1964). Short-circuiting of threat by experimentally altering cognitive appraisal. Journal of Abnormal and Social Psychology, 69, 95-205. 
Leary, M. R., Tate, E. B., Adams, C. E., Batts Allen, A., \& Hancock, J. (2007). Selfcompassion and reactions to unpleasant self-relevant events: The implications of treating oneself kindly. Journal Of Personality and Social Psychology, 92(5), 887-904.

Levitt, J. T., Brown, T. A., Orsillo, S. M., \& Barlow, D. H. (2004). The effects of acceptance versus suppression of emotion on subjective and psychophysiological response to carbon dioxide challenge in patients with panic disorder. Behavior Therapy, 35(4), 747-766.

Lewis, M., Haviland-Jones, J., \& Barrett, L. (2008). Handbook of Emotions. New York, N.Y.: The Guilford Press.

Libby, L. K., Valenti, G., Pfent, A., \& Eibach, R. P. (2011). Seeing failure in your life: Imagery perspective determines whether self-esteem shapes reactions to recalled and imagined failure. Journal of Personality and Social Psychology, 101(6), 1157-1173.

Linehan, M. (1993). Cognitive-behavioral treatment for borderline personality disorder. New York: Guilford Press.

Lissek, S., Rabin, S. J., McDowell, D. J., Dvir, S., Bradford, D. E., Geraci, M., et al. (2009). Impaired discriminative fear-conditioning resulting from elevated fear responding to learned safety cues among individuals with panic disorder. Behaviour Research and Therapy, 47, 111-118. 
Lloyd, C. (1980). Life events and depressive disorder reviewed: II. Events as precipitating factors. Archives of General Psychiatry, 37(5), 541-548

Loo, R., \& Loewen, P. (2004). Confirmatory Factor Analyses of Scores From Full and Short Versions of the Marlowe-Crowne Social Desirability Scale. Journal of Applied Social Psychology, 34(11), 2343-2352.

Lowenstein, G. (2007). Affect regulation and affective forcasting. In J. J. Gross (Ed.), Handbook of Emotion Regulation (pp. 3-24). New York, N.Y.: Guilford Press.

McRae, K., Gross, J. J., Weber, J., Robertson, E. R., Sokol-Hessner, P., Ray, R. D., Ray, R. D., Gabrieli, J. D., \& Ochsner, K. N. (2012). The development of emotion regulation: An fMRI study of cognitive reappraisal in children, adolescents and young adults. Social Cognitive and Affective Neuroscience, 7(1), 11-22.

Merckelbach, H., de Jong, P. J., Muris, P., \& van den Hout, M. A. (1996). The etiology of specific phobias: A review. Clinical Psychology Review, 16, 337-361.

Miller, J., Rude, S.S., \& Haner, M.L. (2015). Experimental modification of appraisal style: Benefits of seeing the big picture. Journal of Experimental Psychopathology, 1, 1-12.

Neely, M. E., Schallert, D. L., Mohammed, S. S., Roberts, R. M., \& Chen, Y. (2009). Self-kindness when facing stress: The role of self-compassion, goal regulation, and support in college students' well-being. Motivation And Emotion, 33(1), 8897. 
Neff, K. D. (2003). The development and validation of a scale to measure self compassion. Self and Identity, 2, 223-250.

Neff, K. D., Kirkpatrick, K. L., \& Rude, S. S. (2007). Self-compassion and adaptive psychological functioning. Journal Of Research In Personality, 41(1), 139-154.

Neff, K. D., Rude, S. S., \& Kirkpatrick, K. L. (2007). An examination of self-compassion in relation to positive psychological functioning and personality traits. Journal of Research in Personality, 41(4), 908-916.

Neff, K. D., \& Vonk, R. (2009). Self-compassion versus global self-esteem: Two different ways of relating to oneself. Journal of Personality, 77(1), 23-50.

Netemeyer, R. G., Bearden, W. O., \& Sharma, S. (2003). Scaling procedures: Issues and applications. Thousand Oaks, CA: Sage Publications Inc.

Nolen-Hoeksema, S., \& Morrow, J. (1991). A prospective study of depression and posttraumatic stress symptoms after a natural disaster: The 1989 Loma Prieta earthquake. Journal of Personality and Social Psychology, 61, 115-121.

Nolen-Hoeksema, S., Wisco, B. E., \& Lyubomirsky, S. (2008). Rethinking rumination. Perspectives on Psychological Science, 3, 400-424.

Pennebaker, J. W., \& Chung, C. K. (2007). Expressive writing, emotional upheavals, and health. In H. Friedman \& R. Silver (Eds.), Handbook of health psychology (pp. 263-284). New York:Oxford University Press. 
Pett, M. A., Lackey, J. R., \& Sullivan, J. J. (2003). Making Sense of Factor Analysis: The Use of Factor Analysis for Instrument Development in Health Care Research. Thousand Oaks, C.A.: Sage Publications, Inc.

Polivy, J., \& Herman, C. P. (2002). Causes of eating disorders. Annual Review of Psychology, 53, 18213.

Raes, F. (2010). Rumination and worry as mediators of the relationship between selfcompassion and depression and anxiety. Personality and Individual Differences, $48,757-761$.

Renner, M. J., \& Mackin, R. (1998). A life stress instrument for classroom use. Teaching of Psychology, 25(1), 46-48.

Rottenberg, J., \& Gross, J., J. (2007). Emotion and emotion regulation: A map for psychotherapy researchers. Clinical Psychology: Science and Practice, 14(4), 323-328.

Rude, S. S. (2011). Thinking contextually about emotionally distressing events. Unpublished manuscript, University of Texas at Austin.

Rude, S. S., Mazzetti, F. A., Pal, H., \& Stauble, M. R. (2011). Social rejection: How best to think about it? Cognitive Therapy and Research, 35(3), 209-216.

Schartau, P. E., Dalgleish, T., \& Dunn, B. D. (2009). Seeing the bigger picture: Training in perspective broadening reduces self-reported affect and psychophysiological response to distressing films and autobiographical memories. Journal of Abnormal Psychology, 118(1), 15-27. 
Skinner, E. A., Edge, K., Altman, J., \& Sherwood, Hayley. (2003). Searching for the structure of coping: A review and critique of category systems for classifying ways of coping. Psychological Bulletin, 129(2), 216-269.

Tabachnick, B. G., \& Fidell, L. S. (2007). Using multivariate statistics (5th ed.). Boston, MA: Allyn \& Bacon/Pearson Education.

Teasdale, J. D., Segal, Z. V., Williams, J. M. G., Ridgeway, V. A., Soulsby, J. M., \& Lau, M. A. (2000). Prevention of relapse/recurrence in major depression by mindfulness based cognitive therapy. Journal of Consulting and Clinical Psychology, 68(4), 615-623.

Vallacher, R. R., \& Wegner, D. M. (1989). Levels of personal agency: Individual variation in action identification. Journal of Personality and Social Psychology, 57(4), 660-671.

Valenti, G., Libby, L. K., \& Eibach, R. P. (2011). Looking back with regret: Visual perspective in memory images differentially affects regret for actions and inactions. Journal of Experimental Social Psychology, 47(4), 730-737.

Van Dam, N. T., Earleywine, M., \& Borders, A. (2010). Measuring mindfulness? An item response theory analysis of the Mindful Attention Awareness Scale. Personality and Individual Differences, 49(7), 805-810.

Verduyn, P., Van Mechelen, I., Kross, E., Chezzi, C., \& Van Bever, F. (2012). The relationship between self-distancing and the duration of negative and positive emotional experiences in daily life. Emotion, 12(6), 1248-1263. 
Watson, D., Clark, L. A., \& Tellegen, A. (1988). Development and validation of brief measures of positive and negative affect: The PANAS scales. Journal of Personality and Social Psychology, 54(6), 1063-1070.

Wegner, D. M., Broome, A., \& Blumberg, S. J. (1997). Ironic effects of trying to relax under stress. Behavioral Research and Therapy, 35(1), 11-21.

Wegner, D. M., Erber, R., \& Zanakos, S. (1993). Ironic processes in the mental control of mood and mood-related thought. Journal of Personality and Social Psychology, 65, 1093-1104. 